\title{
Agile, Web Engineering and Capability Maturity Model Integration: A systematic literature review
}

\author{
C.J. Torrecilla-Salinas ${ }^{a}$, J. Sedeño $^{\text {a,b }}{ }^{\text {, M.J. Escalona }}{ }^{\mathrm{a}}$, M. Mejías $^{\mathrm{a}}$ \\ a Department of Computer Languages and Systems, University of Seville, Spain \\ ${ }^{\mathrm{b}}$ Agencia Andaluza de Instituciones Culturales, Junta de Andalucía, Spain
}

Keywords:

Agile

Scrum

Web Engineering

CMMI

Software Engineering

\begin{abstract}
A B S T R A C T
Context: Agile approaches are an alternative for organizations developing software, particularly for those who develop Web applications. Besides, CMMI (Capability Maturity Model Integration) models are wellestablished approaches focused on assessing the maturity of an organization that develops software. Web Engineering is the field of Software Engineering responsible for analyzing and studying the specific characteristics of the Web. The suitability of an Agile approach to help organizations reach a certain CMMI maturity level in Web environments will be very interesting, as they will be able to keep the ability to quickly react and adapt to changes as long as their development processes get mature.

Objective: This paper responds to whether it is feasible or not, for an organization developing Web systems, to achieve a certain maturity level of the CMMI-DEV model using Agile methods.

Method: The proposal is analyzed by means of a systematic literature review of the relevant approaches in the field, defining a characterization schema in order to compare them to introduce the current state-of-the-art. Results: The results achieved after the systematic literature review are presented, analyzed and compared against the defined schema, extracting relevant conclusions for the different dimensions of the problem: compatibility, compliance, experience, maturity and Web.

Conclusion: It is concluded that although the definition of an Agile approach to meet the different CMMI maturity levels goals could be possible for an organization developing Web systems, there is still a lack of detailed studies and analysis on the field.
\end{abstract}

\section{Introduction}

Since the establishment of Web Engineering as a separate field of Software Engineering [15], it is recognized that Web-based developments are different from classical software development projects and that its specific characteristics will need a specific treatment $[19,21,4,28]$.

Among other specific aspects, Web systems are characterized by a fluidic scope, a flexible approach to requirements and quick userfeedback [41], due to the need to adapt and adjust to changing requirements [43]. This means that the ability to change is a key success factor in Web applications. Thus, Agile methodologies might per-fectly fit Web environments since one of their principles consists in embracing changes [6].
A growing trend towards offering new methods dealing with applying Agile approaches to Web environments started several years ago [3] and different research groups are working on this new line of research [32]. Furthermore, the more popular Web systems become, the more their quality requirements increase.

CMMI-DEV (Capability Maturity Model Integration for Development) is a well-known model that provides organizations with a comparative framework to assess the maturity level reached when developing and acquiring software [13]. The fact of achieving CMMI highest maturity levels relates to product quality improvements [24]. Although there are several proposals for Agile maturity models, CMMI remains by far the most well known maturity model being used by more than 5000 companies all over the world [12].

Thus, an Agile approach to maturity levels based on CMMI could offer organizations developing Web software the opportunity to build quality systems, although keeping their ability to change, as both CMMI and Agile approaches include valid principles for Web software development that are not necessarily incompatible [22].

Even though works regarding the relation between Agile and CMMI started to appear several years ago - we can find papers even from 14 years ago [37] - today both approaches are sometimes 
understood as contrary, as the intense debate among researchers and practitioners shows [16]. Some of the reasons of this mutual reluctance are the bad implementation of both models, the lack of appropriate information and semantic problems [22].

As mentioned above, Web developments require specific treatment and share synergies with Agile approaches. Therefore, and provided that criticisms to Agile methodologies highlight their lack of structure and discipline in comparison with traditional and formal methodologies [8], the possibility of using an Agile approach to reach a certain CMMI maturity level in a Web environment will help institutionalize Agile methods and practices as well as keep the ability to quick response that Agile methods offer to organizations, which is vital in a Web-based development.

Based on the foregoing, this paper aims to cover the following objectives:

- Review systematically the existing literature regarding the relation among Agile methodologies, Web Engineering and CMMIDEV maturity model.

- Characterize the relevant studies, defining a comparative framework in order to better identify the current state-of-the-art.

- Draw relevant conclusions and propose further lines of research.

This paper is organized as follows: After this introduction, Section 2 presents the research method. Section 3 provides the background, including a general idea of Agile methods, Web Engineering and CMMI-DEV together with an overview of the previous existent reviews. Section 4 describes the process carried out to identify and select the studied approaches, as well as offers the comparative framework used to normalize the found approaches. Then, Section 5, based on the defined framework, organizes these approaches by presenting them in a coherent way. Finally, Section 6 analyzes the resultant information and Section 7 states some conclusions and contributions proposing possible future lines of investigation.

\section{Research method}

This paper aims to be a systematic literature review conducted following the approach proposed by Barbara Kitchenham et al. [26]. The process they recommend comprises the phases below:

1. Planning the review. The context and objectives of the review must be delimited to identify the open questions linked to the addressed problems, in order to plan the review. Once they are set, the research questions must be posed as guidelines to cope with the next steps of the process. Finally, the searching protocol is defined with questions such as: "Which sources will the data be searched in?" or "What are the searching criteria and the search strings?"

2. Conducting the review. All relevant approaches are selected and studied according to the constraints described in previous phases. In this phase a common framework is also identified to compare them.

3. Reporting the review. A report with the main conclusions obtained is written, after the relevant approaches are selected and studied.

Fig. 1 shows the different phases of the process.

As mentioned, phase 1 consists in the detailed planning of the review. Fig. 2 depicts the process followed during Phase 1 of the review.

Initially, the main research question will be identified and afterwards decomposed in low-level research questions. Based on them, a set of search strings will be defined and the sources to be searched identified.

Phase 2 consists in performing the review as planned in the previous phase and then, defining a characterization schema to better compare the identified studies. Fig. 3 shows the process followed during this phase.

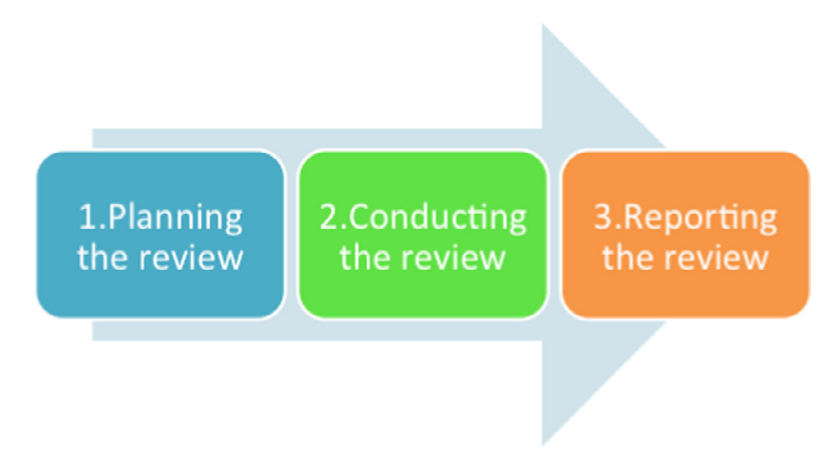

Fig. 1. Systematic review process.

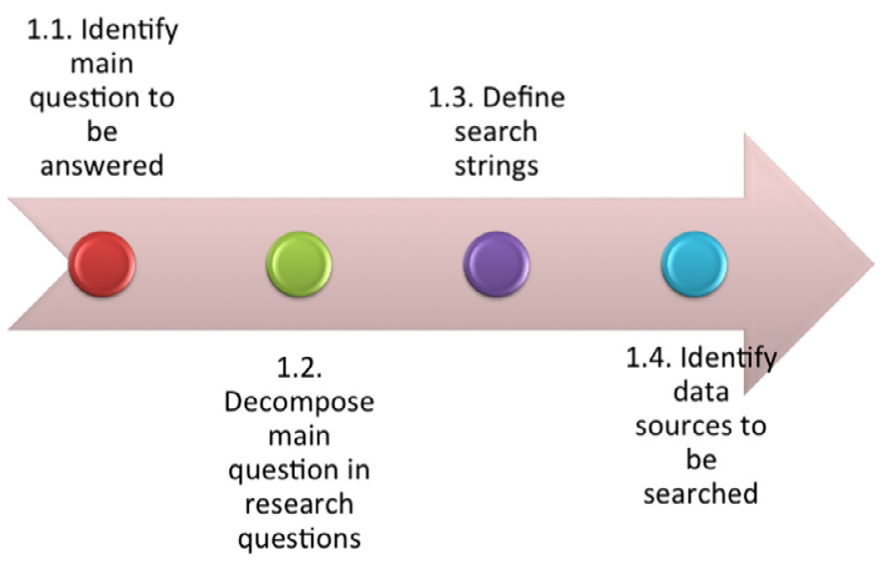

Fig. 2. Phase 1: planning the review.

As shown in Fig. 3, the first step of phase 2 constitutes the initial search and the second one deals with applying a first filter to eliminate duplicated results. The third step is associated with a second screening based on criteria related to the type of paper, date and source of publication.

The fourth step deals with a screening in terms of the title, abstract and keywords, and the fifth one involves the use of a filter according to the full content of the paper. The last phase will consist in the definition of a characterization schema that will allow the comparison of the identified studies.

Finally, the third and last phase consists in drafting a report based on the analysis of the identified papers, extracting relevant conclusions on the defined research questions.

The systematic review reported in this paper tends to clarify the posed problem: Could an Agile approach help an organization reach a certain CMMI maturity model taking into account the special characteristics of a Web-based environment?

The following sections will provide an overview of the approaches related to the problem and they will evaluate their degree of maturity to address the previous question.

\section{Background and related work}

\subsection{Agile methodologies}

During the last decade of the 20th century, a set of methods and techniques appeared in several software development projects. The main goals of this set of practices were, firstly, to ensure that valuable results were delivered to customers and users as soon as possible, and secondly, to allow development organizations to adapt their products to users' changing requirements [6].

Several years after the appearance of these methods in 2001, some of the most recognized practitioners (Kent Beck, Alistair Cockburn, Martin Fowler, Ron Jeffries, Robert C. Martin, Ken Schwaber and Jeff Sutherland) promoted what was known as the "Agile manifesto" [6], 


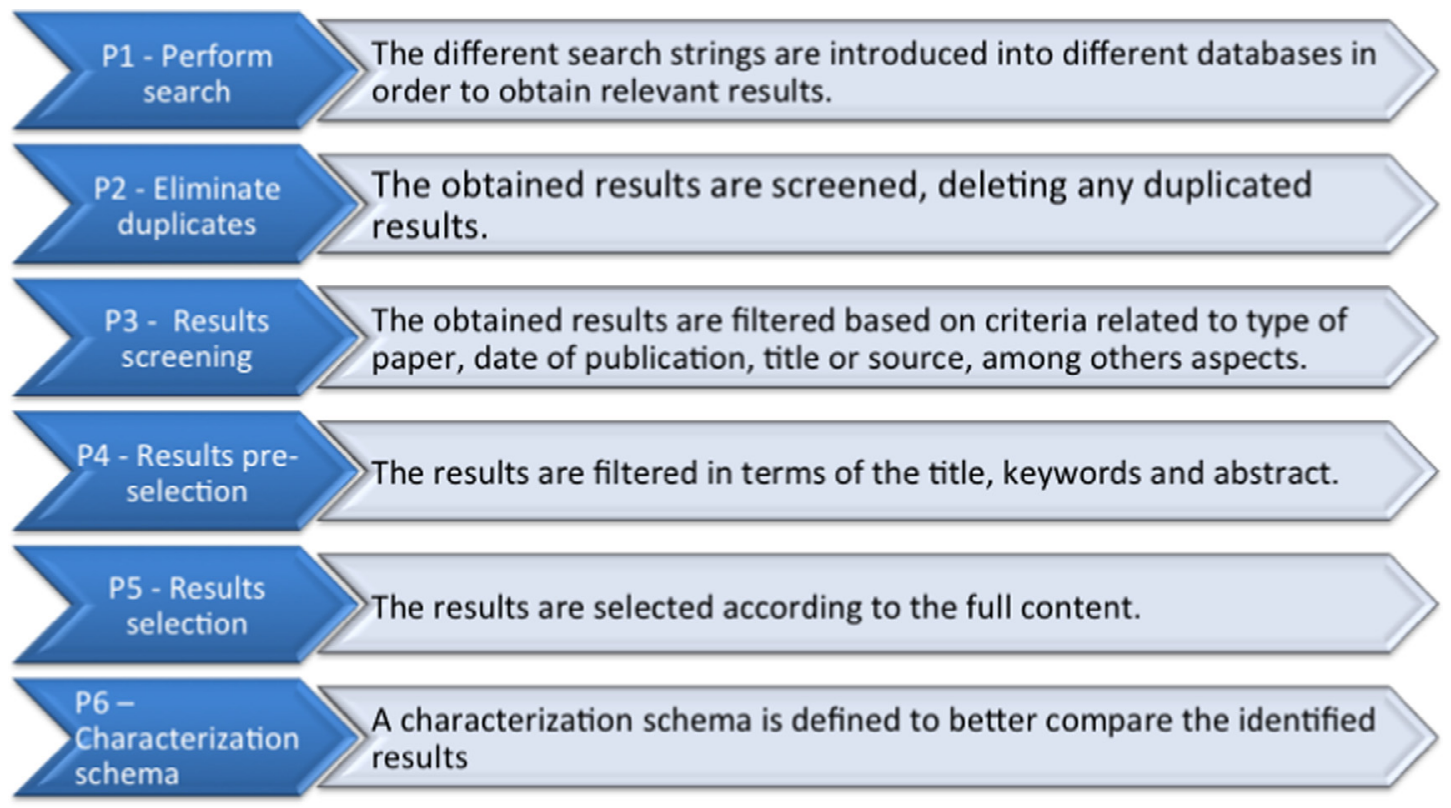

Fig. 3. Phase 1: conducting the review.

which included the general values and principles shared by all of these approaches. Some of those principles were, among others:

- Focusing on quick delivery of value to customer, with short development cycles.

- Adapting to changes, even in late phases of development projects.

- Empowering teams.

- Shortening feedback loops with users and customers.

- Improving internal and external communications.

- Focusing on technical excellence.

Consequently, Agile is considered a "label" that involves a diverse and broad set of techniques, methods and methodologies for software development [22]. Among the most popular Agile methods are: eXtreme Programming (XP) [5], Crystal [14], Scrum [47], Lean Software Development [40] or Kanban [2].

From this time on, Agile methodologies have grown in popularity [7] and nowadays they are being applied to a large number of software and product development projects. It has to be mentioned that, under the label Agile, Scrum is one of the most common method, being used either alone or combined with other Agile techniques, in most of the real-world Agile implementations [38].

\subsection{Web Engineering}

Web Engineering can be defined as the set of techniques, tools and methods that in Software Engineering can help teams develop systems in the Web. Web Engineering has become an accepted discipline in Software Engineering from 2002 to date [15].

In the last years, several methodologies in the Web Engineering area have been proposed. Some of them, such as UWE (UML Web Engineering) [27], IFML (Interaction Flow Modeling Language) from OMG [34], WebML (Web Modeling Languages) [9], HFPM (Hypermedia Flexible Process Modeling Strategy) [35] and NDT (Navigational Development Techniques) [18], among the newest, offer new solutions and are widely accepted by the research community.

All these approaches agree that the characteristics below differentiate Web projects from other software development projects [15]:

- Complex navigational structure [18,20].

- Critical interface requirements (such as unknown users or availability, among others) [18,20].

- Security aspects [25].
- Increase on maintenance efficiency, avoiding downtimes [33].

- Delivery as soon as possible [31,41,42].

- Reduction of "time-to-market" [31,41,42].

- Adaptation to quick-changing requirements [31,41,42].

\subsection{CMMI-DEV}

The Capability Maturity Model Integration is an approach to process improvement that allow organizations to develop effective processes [13]. CMMI includes several models, such as CMMI-DEV, that is the suitable one for software development.

The actual version of CMMI-DEV is 1.3 [13]. CMMI-DEV offers a set of best practices to develop software services and products from their inception to their deployment and maintenance. The actual version of CMMI-DEV is composed of 22 process areas, out of which 16 are common to all CMMI models, 1 is shared and 5 are specific for software development.

Similarly to other maturity models, CMMI-DEV uses a number of levels to recommend organizations the best way to carry out their development processes. These levels are obtained as the final result of an organization's formal evaluation process. CMMI-DEV recommends two different paths for organizations to improve processes called continuous and staged representations.

The staged representation focuses on the global maturity level of an organization, which is considered a way of characterizing its performance. In the staged representation, the organization, by means of each maturity level, improves an important subset of processes preparing it to the next maturity level. A set of generic and specific goals, related to the predefined subset of process areas to improve, has to be achieved to get a certain maturity level. It is worth pointing out that the CMMI-DEV model only includes the goals to meet; therefore the organization must decide how to get them.

Particularly, this work will be focused on the staged representation of the model. The staged representation, in opposition to the continuous representation, introduces improvements gradually; starting with basic management practices and going further with other more complex to finally build each step on the previous one. This representation also permits comparison across and among organizations, having several case studies at their disposal [45].

Typically, the staged representation is recommended if the organization has little experience improving processes [11], which might 


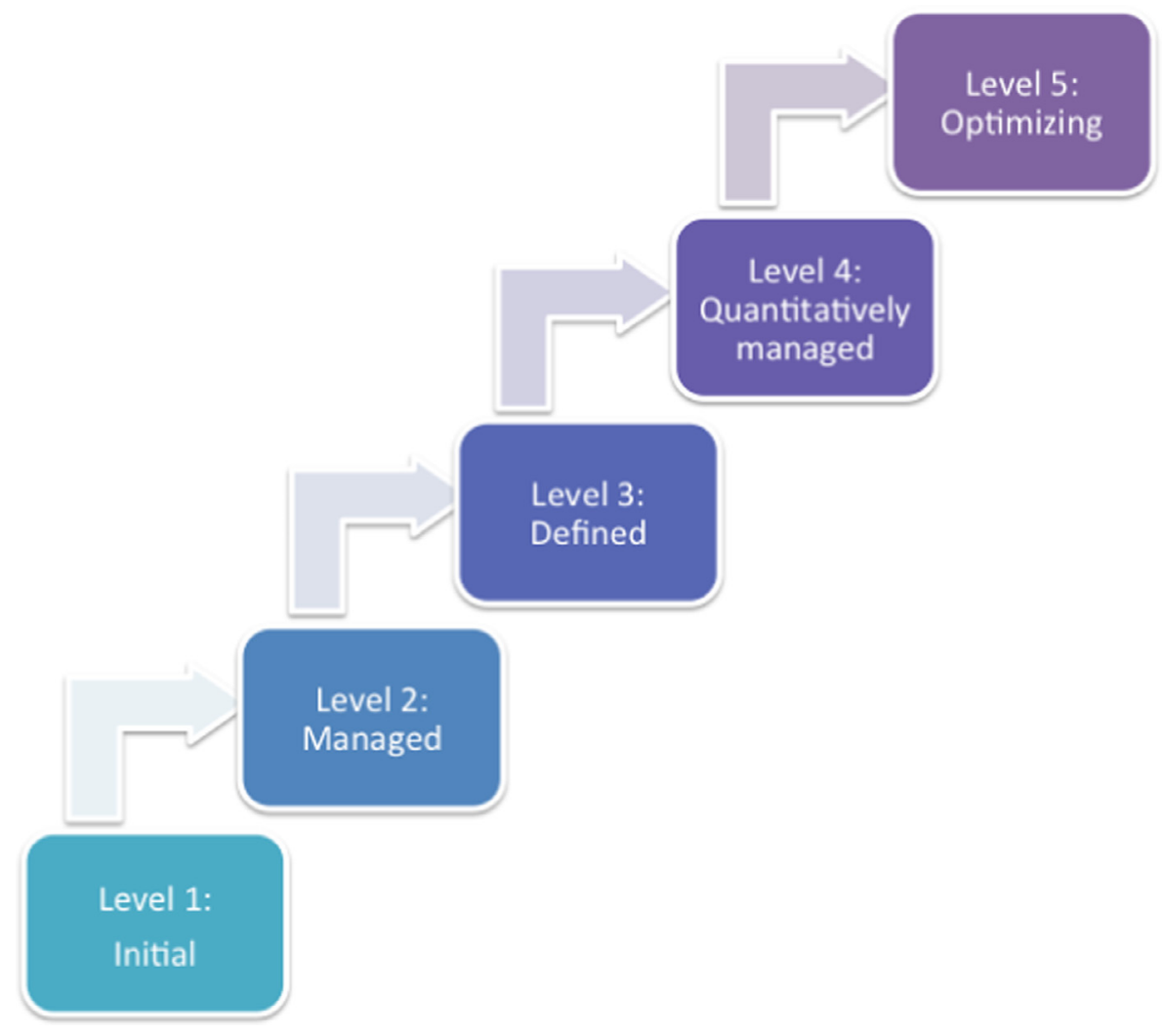

Fig. 4. CMMI staged representation maturity models.

be the case of several small and medium Agile companies developing Web systems.

In the staged representation five different maturity levels are defined, as Fig. 4 shows.

\subsection{Previous reviews}

This section will summarize some systematic reviews linked to the main topics covered in this paper.

Starting with the relation between Agile and CMMI, we can highlight the work by Selleri Silva et al. [44], who review the usage of Agile software development techniques together with CMMI, and discuss their benefits and limitations. This study presents a very complete and comprehensive analysis and covers papers published before 2011. One of its main conclusions is that Agile techniques are useful to reach up to CMMI maturity levels 2 and 3, but they must be combined with additional practices to fully achieve any particular CMMI level.

Although their conclusions are valid and useful for any type of software development projects and also applicable to Web systems, our work will try to identify specific approaches and techniques applied when CMMI and Agile are used together in Web environment projects, highlighting the specific adaptations proposed to Agile methods to fit Web specificities and CMMI goals. Therefore, Selleri Silva et al. analyze in their work more than 80 papers with a special focus on the Agile methodology used to achieve CMMI goals, the maturity level mentioned and the process area implemented, whereas in our study, we will try to focus on identifying works that are analyzing the usage of different Agile techniques to, at the same time, meet CMMI goals as well as fit Web special characteristics. Our work will also include papers published until 2014, providing us with a more updated view of the research questions.

The work by Chagas et al. [10] focuses on Agile Project Management in the context of maturity models. It identifies the different characteristics of Agile project management in organizations using both maturity models and Agile techniques. The paper concludes that both approaches can be jointly implemented, even though there is a lack of details in the literature on how to perform some of the activities. Nevertheless, this particular study mainly analyzes project management aspects of software development.

As the work by Selleri Silva et al., this one differs also from ours in that is not taking into account the specific characteristics of Web Engineering or Web Systems, but it focuses on general software development approaches. In our case, in opposition to this work, we will not limit our study to project management process areas of CMMI.

Finally, we can also find the work by Heeager [23]. This paper studies the combinability or compatibility between some disciplined approaches (including CMMI) and Agile methodologies. It revises the relation among ISO, CMM/CMMI, or Critical Software Development and Agile by means of a literature review. It concludes that disciplined and Agile methods are highly compatible, but not combinable. In contrast, the paper centers on the compatibility of different disciplined approaches, without paying special attention to CMMI. As in the two aforementioned reviews, this one does not consider the relation between the Agile approaches and Web Engineering.

Nevertheless, a systematic literature review [17] regarding Agile has been found out. It gathers papers published before 2005 and investigates benefits and limitations of Agile methods, without putting them together with CMMI maturity models.

In our work, we will assess and present in the next sections a review of the existent literature regarding Agile and CMMI combined approaches in Web development environments.

\section{Planning and conducting the review}

\subsection{Planning the review}

This section presents in detail the process of planning and conducting the systematic review. As mentioned, the first step dealt with setting the context and objectives of the review to identify the open 
Table 1

Research questions.

\begin{tabular}{cc}
\hline No. & Description \\
\hline RQ1 & $\begin{array}{c}\text { This question tries to ascertain whether the Agile approach and CMMI models are in fact compatible in Web projects. This question assesses the "Compatibility" } \\
\text { dimension }\end{array}$ \\
RQ2 & $\begin{array}{c}\text { This question, based on the compatibility between Agile and CMMI models, tends to demonstrate that an Agile approach in a Web environment can fulfill the goals } \\
\text { of a CMMI-DEV process, via a formal assessment or empirical results, for example. This question assesses the "Compliance" dimension }\end{array}$ \\
RQ3 & $\begin{array}{c}\text { This question attempts to identify empirical experiences proving that a certain set of Agile practices can allow a certain CMMI-DEV to reach the maturity level for } \\
\text { Web projects. This question assesses the "Experience" dimension }\end{array}$ \\
RQ4 & $\begin{array}{c}\text { This question tends to uncover what is the highest documented CMMI-DEV maturity level reached by Agile practices in Web projects. This question assesses the } \\
\text { "Maturity" dimension }\end{array}$ \\
RQ5 & $\begin{array}{c}\text { This question focuses on the special characteristics of Web projects that Agile techniques must meet to achieve CMMI goals. This question assesses the "Web" } \\
\text { dimension }\end{array}$ \\
\hline
\end{tabular}

Table 2

Search strings.

\begin{tabular}{lll}
\hline Search string & \\
\hline A1. Agile & B1. CMMI & C1.Web \\
A2. Agility & B2. Capability Maturity & C2. Web \\
& Model & Engineering \\
A3. Scrum & & \\
A4. eXtreme Programming & & \\
\hline
\end{tabular}

questions related to the research problem. Thus, we can establish the main objectives of the review. The main goals are listed below:

- Identifying the state-of-the-art in relation to the Agile approach to maturity models in Web environments.

- Describing the proposed solutions and the research methods used for these proposals.

- Defining a characterization schema and characterizing the identified studies based on it in order to evaluate the existing gaps.

As our main objectives concern, the general question to answer was: "Is it possible that an Agile approach can help an organization reach a certain maturity model suitable for the special characteristics of a Webbased environment?". It is a very general question to address; in consequence, we structured it into the following research questions:

- RQ1: What is the relation between CMMI-DEV maturity levels and Agile methodologies in Web environments?

- RQ2: What evaluation criterion concludes that an Agile technique is compliant with certain goals of a CMMI-DEV process area in Web environments?

- RQ3: What experiments or case studies could validate an Agile approach to maturity models in Web environments?

- RQ4: What is the highest documented maturity level that can be reached using Agile approaches in Web environments?

- RQ5: How could Web specific characteristics be addressed through Agile methods so as to reach CMMI-DEV goals?

Table 1 describes in detail the aforementioned research questions and links each one of them to a dimension of the analyzed problem. Subsequently, we will use these dimensions to define the characterization schema that will help compare the identified studies:

After raising the research questions to answer and before starting with the search process, a systematic search strategy was designed. It focused on consulting the key conference and workshop papers as well as journal articles in the main existing digital libraries.

For this purpose, it was crucial to define the search strings used before planning the search strategy. They are established according to the pattern (A1 OR A2 OR A3 OR A4) AND (B1 OR B2) AND (C1 OR $\mathrm{C} 2$ ), after running some tests. The search expressions are shown in Table 2.

The first criterion refers to Agility; we decide to include two particular Agile methodologies (Scrum and eXtreme Programing) together with the most general terms "Agile" and "Agility" when select-
Table 3

Selected databases.

\begin{tabular}{lll}
\hline No. & Database & Search Fields \\
\hline D1 & IEEE Xplore & Title, Abstract, Keywords \\
D2 & Wiley InterScience Journal Finder & All fields \\
D3 & Springer Link & N/A \\
D4 & ACM Digital Library & Title, Abstract, Review \\
D5 & Science Direct & Title, Abstract, Keywords \\
\hline
\end{tabular}

Table 4

Inclusion criteria.

\begin{tabular}{ll}
\hline No. & Criteria \\
\hline C1 & The paper is written in English \\
C2 & The paper is published after January 2001 and before March 2015 \\
C3 & The paper is related to Computer Science \\
C4 & The paper is not an editorial, preface or discussion \\
C5 & The paper is published \\
C6 & The paper present an analysis based on CMMI staged representation \\
\hline
\end{tabular}

Table 5

Search results.

\begin{tabular}{lllllll}
\hline & $\begin{array}{l}\text { D1 } \\
\text { Results }\end{array}$ & $\begin{array}{l}\text { D2 } \\
\text { Results }\end{array}$ & $\begin{array}{l}\text { D3 } \\
\text { Results }\end{array}$ & $\begin{array}{l}\text { D4 } \\
\text { Results }\end{array}$ & $\begin{array}{l}\text { D5 } \\
\text { Results }\end{array}$ & Total \\
\hline Results after P1 & 695 & 388 & 1,142 & 1,091 & 704 & 4020 \\
\hline
\end{tabular}

ing the search string, as they are doubtlessly the most popular Agile method [38].

The second criterion concerns maturity models, although the term CMMI-DEV is not included to avoid narrowing the results in excess.

Finally, terms such as "Web" and "Web Engineering" focus the scope of the results on the Web engineering field.

The sources to perform the review were chosen once the search strings were defined. Table 3 lists the selected databases including the used search fields:

Finally, the inclusion criteria to be applied to the results screening were defined and they are shown in Table 4.

\subsection{Conducting the review}

The review process comprises six steps and the results were registered in Zotero [53] and Excel spreadsheets, in order to organize the search tasks. Zotero is a tool that favors quick references collection and organization, and duplicates detection.

As previously stated, the first step of this review deals with the consultation of several sources using different search strings. Table 5 shows the initial search results:

Most databases provide results export on BibTex format, which is compatible with Zotero, except Springer and ACM. In these cases, a text export was performed and small Python scripts were developed to transform the text files into BibTex format. 
Table 6

Search results without duplicates in the same database.

\begin{tabular}{|c|c|c|c|c|c|c|}
\hline & D1 results & D2 results & D3 results & D4 results & D5 results & Total \\
\hline Results after P1 without duplicates in the same data base & 369 & 150 & 449 & 435 & 249 & 1652 \\
\hline
\end{tabular}

Table 7

Search results after deleting all duplicates.

\begin{tabular}{lll}
\hline First results & Duplicated results & Results after P2 \\
\hline 1652 & 199 & 1453 \\
\hline
\end{tabular}

Table 8

Search results after P3, P4 and P5.

\begin{tabular}{lr}
\hline & Results \\
\hline Results after P2 & 1453 \\
Discarded on P2 & 197 \\
Results after P3 & 1256 \\
Discarded on P3 & 1161 \\
Results after P4 & 95 \\
Discarded on P4 & 65 \\
Results after P5 & 6 \\
\hline
\end{tabular}

All the resultant data in BibTex were registered both in a Zotero database and Excel spreadsheets, in order to organize the results and delete any duplicate.

Tables 6 and 7 outline the total results removing all duplicates, once phase 2 was performed:

As Section 2 states, the results in phase P3 were assessed by filtering them according to the criteria previously presented in Table 1. If the paper did not fulfill all inclusion criteria, it was discarded. The fourth phase consisted in selecting works in terms of title, keywords and abstract choosing those related to the main research questions previously mentioned. Finally, the last phase comprised a screening regarding a detailed analysis of the full content of the article. Table 8 presents the results after phase P3, P4 and P5:

It must be kept in mind that in this last phase, we focused on papers analyzing the relation between existing Agile practices and CMMI maturity models, not for new maturity model proposals based on Agile practices. It is worth mentioning that we were not able to find any paper analyzing the relation among Agile, Web Engineering and CMMI continuous representation.

It is also important to mention that within phase 5, an initial set of 30 papers was selected, since they were potentially related to the topic. From this initial set, a total of 24 were discarded, as they were not directly related to Web systems. Nevertheless, they might be of interest for the research community since some of them were not included on the existing reviews. So the result of the analysis of this other 24 papers has also been included in Annexes A and B.

It is worth mentioning that the main researcher performed the search and two other researchers reviewed the set of selected works to ensure its correctness.

Table 9 lists the selected works.

We can also highlight that only 1 of these 6 distinguished papers [46] was identified and included in the work by Selleri et al., as it
Table 10

Proposed characterization schema.

\begin{tabular}{|c|c|c|}
\hline Dimension & Indicator & Dominion \\
\hline \multirow[t]{3}{*}{ Compatibility } & State-of-the-art analysis & $\{$ High, Medium, Low $\}$ \\
\hline & Starting point & \{Agile, CMMI, Both\} \\
\hline & Approaches & (string+) \\
\hline \multirow[t]{2}{*}{ Compliance } & Assessment & $\begin{array}{c}\text { \{Theoretical, Empirical, Formal } \\
\text { assessment, No assessment }\end{array}$ \\
\hline & Analysis & $\{$ Deep, Medium, Low, N/A $\}$ \\
\hline \multirow[t]{5}{*}{ Experience } & Experiment/case study & $\{$ Yes, No $\}$ \\
\hline & Size of organization/project & $\begin{array}{l}\text { \{Big, Medium, Small, No details, } \\
\quad \text { N/A }\}\end{array}$ \\
\hline & Number of projects & ((number)|No details) \\
\hline & Format & $\begin{array}{l}\text { \{Paper, Short paper, Book } \\
\text { chapter }\}\end{array}$ \\
\hline & Type & $\begin{array}{l}\text { \{Journal, National Conference, } \\
\text { International Conference }\end{array}$ \\
\hline \multirow[t]{2}{*}{ Maturity } & Maturity level & ([1-5]|No details) \\
\hline & Coverage level & \{Full, Partial, No detail $\}$ \\
\hline \multirow[t]{2}{*}{ Web } & Navigation \& interfaces & ((string)|No details) \\
\hline & $\begin{array}{l}\text { Delivery \& adaptation to } \\
\text { changes }\end{array}$ & ((string)|No details) \\
\hline
\end{tabular}

only covers studies published before 2011. The different structure of the search strings might also explain why Selleri et al. did not identify the work by [39].

The sixth and final step that follows the systematic review consisted in the definition of a characterization schema that may allow comparing each of the identified studies. This schema will make available easier comparisons available and will help respond our general question, "Is it possible that an Agile approach can help an organization reach a certain maturity model suitable for the special characteristics of a Web-based environment?" as well as the derived research questions.

We recommend a set of indicators to evaluate each of the identified dimensions, after considering the aforementioned questions, as presented in Table 1. Table 10 summarizes these dimensions together with the associated indicators and each dominion:

Table 10 outlines the possible values of each indicator through regular expressions, which are further explained below.

The following identified indicators are suggested with regard to the "Compatibility" dimension:

- State-of-the-art analysis: It analyzes the "state-of-the-art" attending to the possibility of using Agile methods to reach a certain CMMI-DEV maturity model.

- Starting point: It evaluates whether the study starts from either Agile area to reach a certain maturity level or from CMMI area to light the development process.

- Approaches: It presents which of the Agile approaches (meaning methods, techniques and practices) are proposed to reach a certain CMMI-DEV maturity model.

Table 9

Selected results.

\begin{tabular}{|c|c|c|c|}
\hline Ref. & Name & Authors & Year \\
\hline A1 & Mapping Agile Practices to CMMI-DEV level 3 in Web Development Environments & Torrecilla Salinas, C.J.; Escalona,, M. J.; Mejías, M. & 2014 \\
\hline A2 & Speculation of CMMI in Agile methodology & Aggarwal, S. K.; Deep, V.; Singh, R. & 2014 \\
\hline A3 & Combining maturity with agility: lessons learnt from a case study & Tuan, N. N.; Thang, H. Q. & 2013 \\
\hline A4 & A Scrum-Based Approach to CMMI Maturity level 2 in Web Development Environments & Torrecilla Salinas, C.J.; Escalona„, M. J.; Mejías, M. & 2012 \\
\hline A5 & Using Scrum to guide the execution of software process improvement in small organizations & Pino, F. J.; Pedreira, O.; García, F.; Luaces, M. R.; Piattini, M. & 2010 \\
\hline A6 & Why a CMMI level 5 Company Fails to Meet the Deadlines? & Smite, D.; Gencel, C. & 2009 \\
\hline
\end{tabular}


Table 11

Analysis of the selected studies.

Study Analysis

A1 This study theoretically combines different Agile practices that may allow covering all specific and generic goals of CMMI maturity level 3, specifically in Web development environments. Besides, it evaluates practices derived from different methodologies and maps them to the different process areas of CMMI level 3. This study, published in an international conference, does not include any relevant case study or experience that could validate its proposal.

It is a continuation of [A4], so its proposed mapping is starting from a modified version of Scrum, to which several other Agile methodologies or techniques are added.

The work also tries to match the proposed Agile techniques with the specific Web characteristics, like interfaces and short feedback periods.

A2 This work, published in the proceedings of an international conference, proposes to implement the essential principles of CMMI maturity model by means of Agile processes, defining a model of people interaction in terms of Agile principles. It does not present any type of mapping between Agile practices and the different CMMI goals or proposes any specific Agile methodology.

It also includes a case study of a company developing Web projects and states the potential suitability of Agile for Web environments. In the presented case study some of the CMMI goals are achieved using Agile principles and the results are tested by means of a self-assessment.

It concludes that the essence of CMMI can be applied using Agile approaches.

The case study is only presented at high level without detailed results supporting the study conclusions.

A3 In this paper, extracted from the proceedings of an international conference, the authors present a case study of a Dutch company developing Web-based software. The company is developing Web systems based on Agile approaches (mainly a joint Scrum/XP implementation). The company also holds some software quality certifications and tries to apply them into the ITIL framework.

The authors of the paper try to determine a relation between Agile practices and CMMI maturity level 2 and 3, oriented towards reducing waste and increase both delivered value and customers' satisfaction.

The authors present a mapping between CMMI processes and Agile practices, which does not go down to goal level, stating that most of CMMI level 2 and 3 process areas could be covered by this Agile implementation, although a formal assessment is not reported.

The paper also reports an increase in delivery speed and customers' involvement, after using Scrum and some eXtreme Programming practices. Nevertheless, it also shows some problems when scaling Agile practices.

A4 This paper studies how feasible is to achieve CMMI maturity level 2 using Scrum standard practices and techniques for Web development projects results.

Besides, it includes a "state-of-the-art" analysis of the question and it theoretically assesses whether Scrum techniques can be used or not to achieve the goals of all CMMI level 2 process areas for Web environments.

As a main conclusion, it states that Scrum practices cannot achieve all CMMI specific and generic goals on their own, although they can be used as a starting point. It also proposes, from the conclusions of its assessment, an extension to Scrum based on other Agile methods (like XP) or ad-hoc modifications, to cover the identified gaps.

The paper, published in an international conference, does not include any experiment or case study that could validate its conclusions, remaining only at a theoretical level.

A5 This work, published in "Journal of Systems and Software", describes by means of a case study, a process-improvement method based on Scrum that is applied to two small companies developing Web systems, one of them being assessed to achieve CMMI maturity level 2.The conclusions of the paper show how Scrum can be used both to improve and formalize processes and at the same time to help a real company go through a CMMI level 2 formal assessment, although results of the assessment are not provided within the conclusions of the paper.The paper does not map CMMI goals to Agile practices, since its main focus is the general process improvements, but it provides a link to a real life Web company using Scrum as a facilitator to achieve CMMI level 2 in Web environments.

A6 This study, published in a research journal, analyzes a project conducted by a CMMI level 5 company developing Web-based software and using Agile techniques, which was not able to meet its initial plan constraints.

The paper describes how the company developed a relevant distributed Web project with significant deviations from the initial plan. This project shows how elements such as the lack of experience on the platform, technology and engineering methods and the underestimation of complexity can affect negatively. In addition, the authors remark that the lack of knowledge in Agile could also affect the results.

The paper does not present a detailed mapping of the Agile techniques used or how they related to the different CMMI goals, as the company was already CMMI certified, but it shows the growing interest on Agile that even organizations with a well-structured process might have in Agile.

- The following indicators are proposed for the "Compliance" dimension:

- Assessment: It studies the approach regarding how to prove the compliance of an Agile technique with the goal of a CMMI-DEV process.

- Analysis: It describes the level of analysis performed: A deep analysis includes a detailed description of the Agile technique used to achieve every goal of a CMMI-DEV process. A medium analysis develops a high-level overview on how to achieve each goal using Agile practices. A low-level analysis produces a non-detailed overview on how to achieve these goals.

The indicators related to the "Experience" dimension are described below:

- Experiment/case study: It evaluates whether the proposed approach is tested by means of one or several empirical experiences.

- Size of organization/project: It describes the size of the organization or project used to assess the approach.

- Number of projects: It gathers the number of projects used to validate the presented approach.

- Format: It identifies the nature of available documentation for the described projects.

- Type: It identifies where the research was published, either in a national conference, an international conference or in a research journal.

\section{The indicators proposed for the "Maturity" dimension are:}

- Maturity level: It assesses the highest CMMI-DEV maturity level the work identifies an Agile approach can reach.

- Coverage level: It questions whether all goals of both processes of the maturity level, specific and generic, are analyzed or not.

We will analyze what the proposed techniques to fulfill the special characteristics of Web systems are. For this purpose, the indicators proposed for "Web" dimension are:

- Navigation \& interface: It assesses if the special navigation and interfaces phases of Web systems can be designed using Agile techniques which, at the same time, will help reach CMMI goals.

- Delivery \& adaptation to changes: It questions whether there are any Agile techniques that may combine the possibility of reducing "time-to-market", quick delivery value and feedback loops to adapt to changes, as Web systems require, together with the achievement of CMMI goals.

\section{Characterization of studies}

In this section each one of the selected studies will be assessed against the presented characterization schema with the aim of pointing out all existing approaches and their maturity levels.

As an initial approach, Table 11 outlines a qualitative text analysis per each study. 
Table 12

Characterization of studies.

\begin{tabular}{|c|c|c|c|c|c|c|c|}
\hline Dimension & Indicator & {$[\mathrm{A} 1]$} & {$[\mathrm{A} 2]$} & [A3] & [A4] & [A5] & [A6] \\
\hline \multirow[t]{3}{*}{ Compatibility } & State-of-the-art analysis & High & Low & Medium & High & Low & Low \\
\hline & Starting point & Agile & Agile & Agile & Agile & Both & CMMI \\
\hline & Approaches & $\begin{array}{l}\text { Scrum, XP, Lean and } \\
\text { other Agile practices }\end{array}$ & Agile & $\begin{array}{l}\text { Scrum, XP and } \\
\text { ad-hoc extension }\end{array}$ & $\begin{array}{l}\text { Scrum, XP and } \\
\text { ad-hoc extension }\end{array}$ & Scrum & Agile \\
\hline \multirow[t]{2}{*}{ Compliance } & Assessment & Theoretical & Empirical & Theoretical & Theoretical & Empirical & Empirical \\
\hline & Analysis & Medium & Low & Low & Deep & $\mathrm{N} / \mathrm{A}$ & Low \\
\hline \multirow[t]{5}{*}{ Experience } & Experiment/case study & No & Yes & Yes & No & Yes & Yes \\
\hline & $\begin{array}{l}\text { Size of } \\
\text { organization/project }\end{array}$ & $\mathrm{N} / \mathrm{A}$ & Medium & Medium & $\mathrm{N} / \mathrm{A}$ & Small & Large \\
\hline & Number of projects & 0 & No details & No details & 0 & No details & 1 \\
\hline & Format & Paper & Short paper & Paper & Short paper & Paper & Paper \\
\hline & Type & $\begin{array}{r}\text { International } \\
\text { conference }\end{array}$ & $\begin{array}{r}\text { International } \\
\text { conference }\end{array}$ & $\begin{array}{r}\text { International } \\
\text { conference }\end{array}$ & $\begin{array}{r}\text { International } \\
\text { conference }\end{array}$ & Journal & Journal \\
\hline \multirow[t]{2}{*}{ Maturity } & Maturity level & 3 & No details & 3 & 2 & 2 & 5 \\
\hline & Coverage level & Full & No details & Partial & Full & No details & No details \\
\hline \multirow[t]{2}{*}{ Web } & Navigation \& interfaces & Personas, Storyboards & No details & No details & No details & No details & No details \\
\hline & $\begin{array}{l}\text { Delivery \& Adaptation } \\
\text { to changes }\end{array}$ & Scrum, XP, Lean & No details & $\begin{array}{l}\text { Scrum, XP and } \\
\text { ad-hoc extension }\end{array}$ & $\begin{array}{l}\text { Scrum, XP and } \\
\text { ad-hoc extension }\end{array}$ & Scrum & No details \\
\hline
\end{tabular}

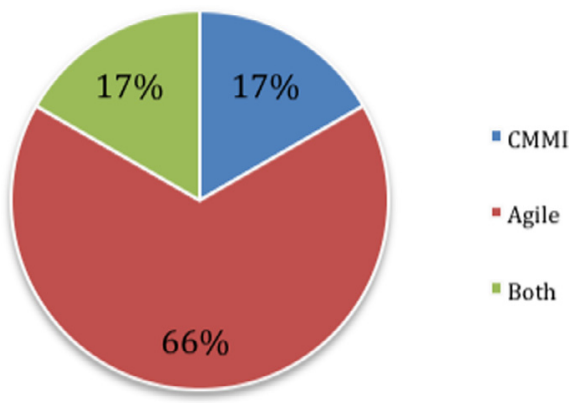

Fig. 5. Starting point for the compatibility analysis.

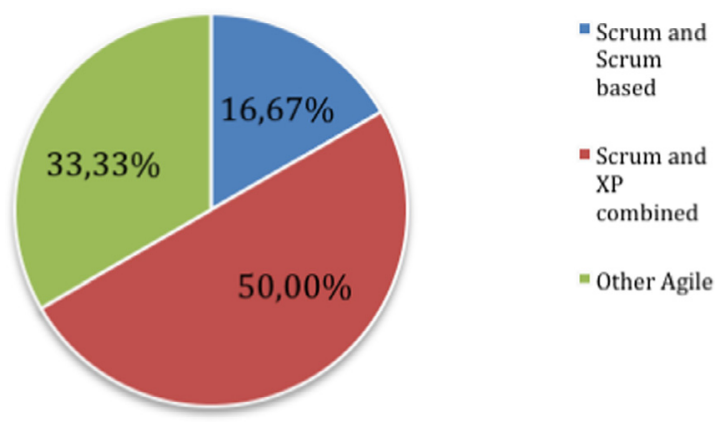

Fig. 6. Used Agile Agile approaches.
Table 12 presents the evaluation results of each of the studies against the defined characterization schema.

\section{Analysis}

This chapter deals with each dimension of the defined characterization schema, summarizing the characterization results of the selected studies.

\subsection{Compatibility}

Concerning "Compatibility" dimension, Fig. 5 represents the different starting points used to assess compatibility between Agile techniques and the CMMI model. As it can be observed, there are compatibility analyses derived from both CMMI and Agile fields (with a majority on the Agile side) and also a study that copes with the assessment using both approaches at the same time. This fact might show mutual interest of both parts in demonstrating compatibility by considering all benefits of the other part. Moreover, the fact of having specifically more studies derived from the Agile side means that this area considers at "respectability" and "institutionalization", which can help spread its practices.

Fig. 6 summarizes the results obtained from the use of Agile approaches. Scrum and XP combined are the main Agile approaches to test compatibility with CMMI in Web environments, as represented below. This result is in line with the expectations, as they are the most widely used Agile methodologies. This analysis also reveals that Scrum is the cornerstone for project and process compliance while $\mathrm{XP}$ plays the same role for engineering practices.

As Table 12 shows, it must be highlighted that half of the papers $[50,52]$ and $[51]$ propose modifications to standard Agile techniques (we can name them ad-hoc extensions) trying to cover some of the identified gaps between the standard methodology used and some of the CMMI goals or Web characteristics.

In addition, Fig. 6 confirms that in two of the analyzed studies $[1,46]$ the approach is not based on a specific Agile methodology or technique, but just based on "Agile" as a generic label, including references to common Agile principles. As mentioned above, generic Agile principles share synergies with Web engineering characteristics and they can also be relevant to the analyzed problem.

Out of the analyzed six studies, two of them are theoretical analyses $[50,51]$ and four of them case studies in which the relation between Agile and CMMI in Web environments is analyzed in practice $[1,52,39,46]$.

The two theoretical studies $[50,51]$ provide a high level, state-ofthe-art theoretical analysis, whereas the others, those reporting case studies, do not include a deep analysis of the previous work, but focus on the results of their reported projects.

Another interesting fact to highlight is that published specific examples of Web project start to appear from 2009 onwards, what can also point to an emerging interest in this research field.

As a main conclusion for the compatibility dimension, we can state that the studied literature shows that Agile and CMMI can be compatible for Web environments, although there is still a lack of published papers on Web specificities. This compatibility will be achieved mainly on Scrum, XP, both of them jointly or a derived method from them.

\subsection{Compliance}

Fig. 7 shows the results of the type of assessment regarding "Compliance" dimension and Fig. 8 displays the type of analysis performed: 


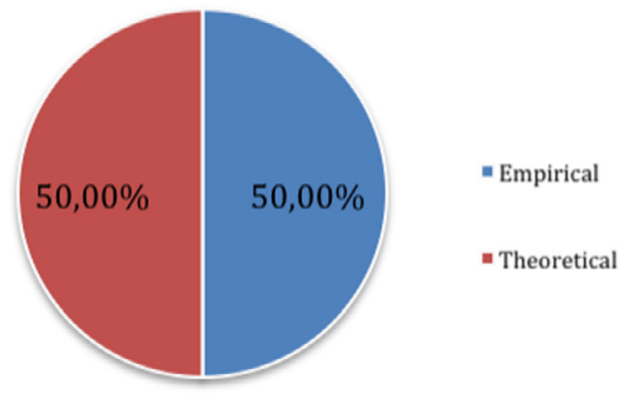

Fig. 7. Type of assessment.

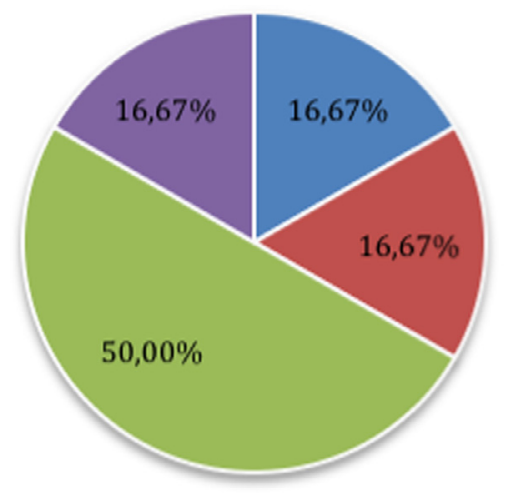

Fig. 8. Type of analysis.

If we examine Fig. 7, we find out that works are evenly distributed among theoretical approaches that analyze mapping between certain Agile approaches and CMMI practices and empirical studies without formal CMMI assessment. As previously mentioned, we find two theoretical works for Web projects analyzing the mapping to CMMI maturity level 2 [51] and level 3 [50], and three case studies such as $[52,39]$ and [46]. The work of [1] includes both a case study and a mapping, but it is performed at very high level, without analyzing CMMI goals in detail.

The theoretical studies enable the definition of mappings between the different CMMI goals and Agile practices, whereas the different case studies try to prove if those mappings are correct or not. One of the main gaps is that no formal CMMI assessment from a Web development organization has been found. Only one of the analyzed papers [39] reports the intention of the company to go through this process but does not include its results.

Fig. 8 represents that almost half of the studies do not analyze the mapping in depth. These are mainly different industry reports and case studies, most of them further explaining how a particular project or company faced the achievement of a CMMI maturity level using Agile practices or how a CMMI certified company tried to apply Agile techniques. The theoretical studies are, in general, assessing the mapping of certain CMMI goals and Agile practices in depth but they do not include any experiments or case studies.

The main conclusion for the compliance dimension is that there is a variety of ways to approach the problem, both from the theoretical and empirical point of view, normally from a deeper analysis in the case of the former. We noticed the lack of a detailed mapping proposal between Agile and all CMMI maturity levels for Web environment that could be validated by an implementation, providing detailed results.

\subsection{Experience}

Fig. 9 summarizes the results of introducing case studies or empirical tests into the studied work, according to the "Experience" di-

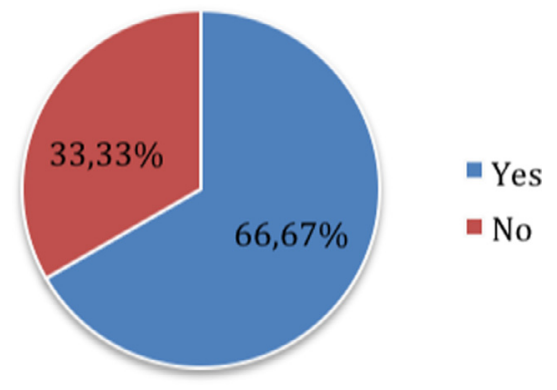

Fig. 9. Inclusion of experiments or case studies.

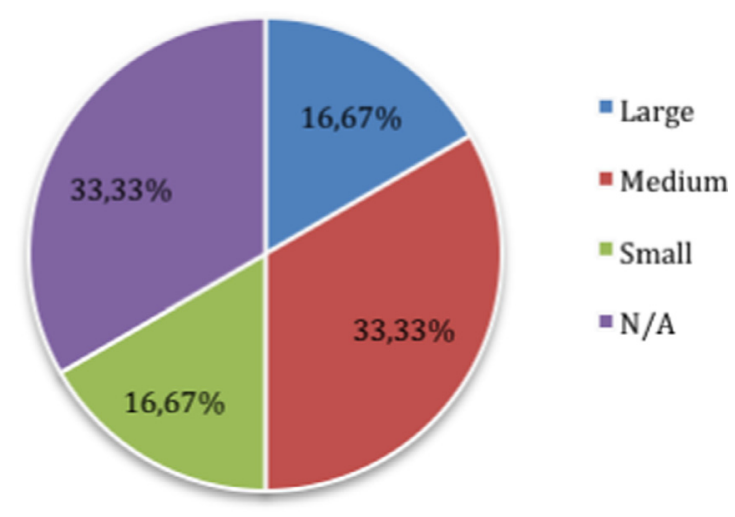

Fig. 10. Size of organization/project.

mension and Fig. 10 states the different sizes of the projects and organizations running the experiment or case studies:

From the analysis of Fig. 9 we can conclude that most of the papers do include experiments or case studies. As mentioned these papers are reporting the results of one or several Web projects involving CMMI and Agile.

Fig. 10 shows that most of the projects and organizations running the different experiments or case studies are either small or medium, while only one of them is large. In particular one of the papers is linked to a small organization [39], two of them to a medium company $[1,52]$ and the remainder is associated with a large distributed project [46].

It is particularly important to highlight the results reported by two of the papers [52,46], which identify problems on scaling Agile for Web projects, even in CMMI certified companies. This is in line with the main debate about the feasibility of scaling Agile approaches on development projects.

To conclude, it must be stated that around $40 \%$ of the works studied are short papers whereas the rest are full papers, all included in journals and conferences. Fig. 11 shows the yearly distribution of the selected studies:

Fig. 11 also proves that the papers regarding the relation between Agile, CMMI and Web Engineering have been published quite recently (the first one appearing in 2009). This shows a growing and recent interest on the topic.

It is also relevant to point out that, the fact that most of these papers were published after 2011 explains why they were not included in previous reviews.

As a main conclusion for the experience dimension, it must be added that we can also find a variety of case studies to test the compatibility of Agile and CMMI and the compliance of the goals of a particular maturity level, including large, medium and smallsized projects, both with good and bad results. These papers have been published in many sources, starting from 2009 and arousing an 


\section{Number of studies per year}

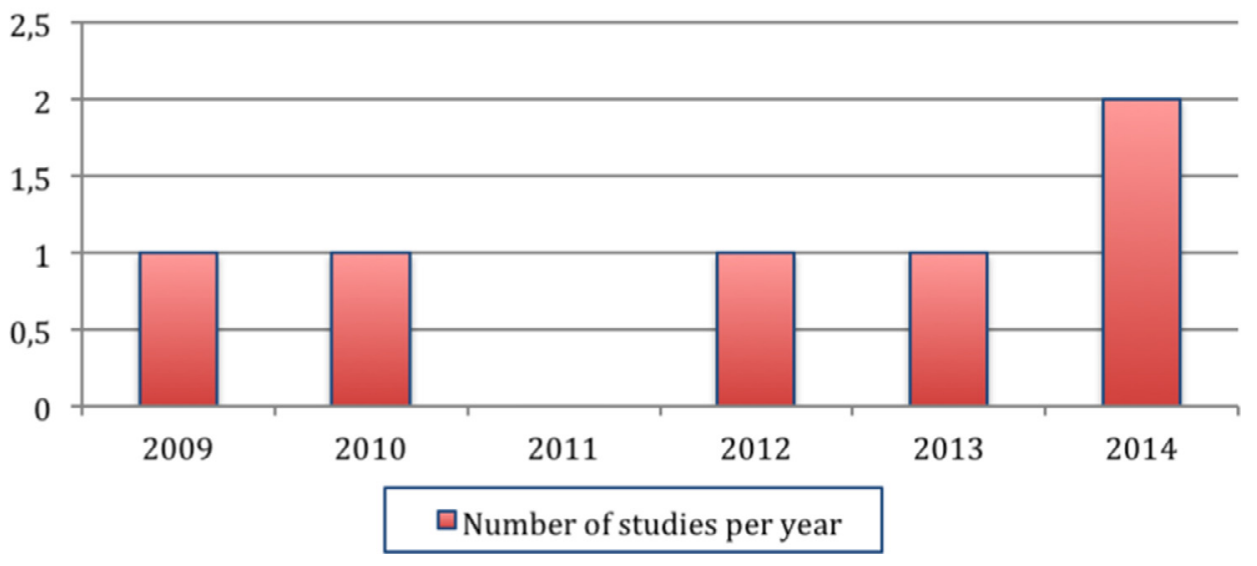

Fig. 11. Yearly distribution of the selected studies.

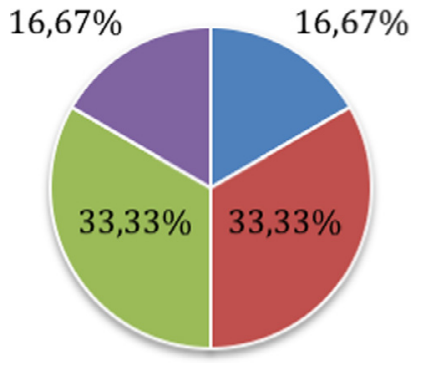

Fig. 12. Maturity level.

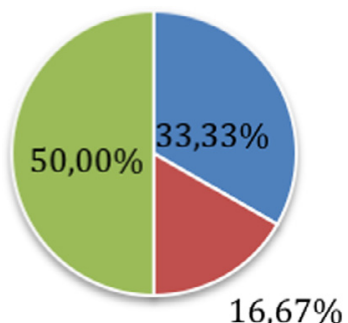

Fig. 13. Coverage level.

emerging interest in the last years. Nevertheless, as a gap, no case study reporting a real formal assessment was found.

\subsection{Maturity}

Fig. 12 shows the maturity levels covered by the studied papers concerning "Maturity" dimension and Fig. 13 displays the coverage level of the performed analysis, if done:

Fig. 12 shows that most of the studies are focusing on levels 2 and 3 , although there is one study [46] from a CMMI certified company at maturity level 5 . Nevertheless, in this experience the company was already assessed and the work does not mention if this process was performed only with Agile methods.

Summarizing, two of them are linked to CMMI level 3 [50] and [52], two of them to level 2 [51] and [39], and one of them to level 5 [46]. The remaining paper offers no information on a specific maturity level [1].

Agile techniques mostly fit on maturity levels 2 and 3, as most of the works analyzed by Selleri et al., when dealing also with Web environments. This is also due to the fact that levels 2 and 3 process areas concern project and engineering issues, which are the natural scope of the most common Agile techniques, like Scrum and XP, whereas

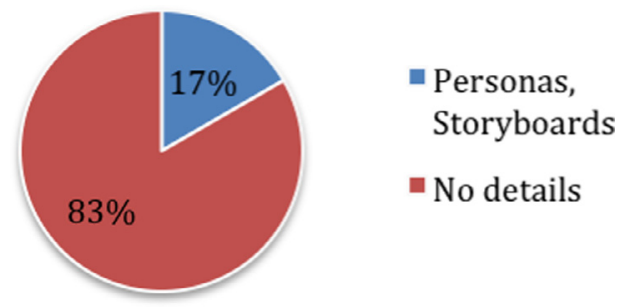

Fig. 14. Navigation and interfaces.

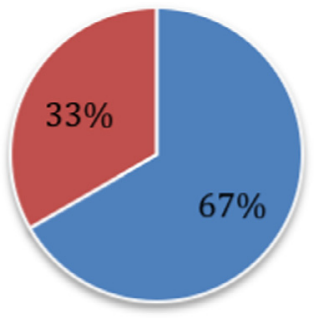

- Scrum and XP

- No details

Fig. 15. Delivery and adaptation to changes.

level 4 and 5 are more associated with organizational issues. Therefore, we can state that there is a lack of analysis, either theoretical or experimental on Agile approaches for the highest maturity levels of CMMI in Web environments.

Fig. 13 also shows that the majority of the given works do not provide a full analysis of all generic and specific practices, but either a partial or high-level mapping, or no mapping at all.

We can notice that two of them include a detailed coverage analysis [50] and [51], but no experience or case study, whereas the others include either high-level or not detailed mapping analysis.

As a main conclusion for the maturity dimension, it must be summed up that we can find works presenting the usage of Agile practices in different CMMI maturity levels for Web environments, but the main focus remains at levels 2 and 3. Nonetheless, there is a lack of comprehensive and detailed studies that will map all the different specific and generic goals of all CMMI maturity levels to a set of Agile practices in Web environments.

\subsection{Web}

Figs. 14 and 15 display the identified practices to cover aspects of Web characteristics, even if the work is not specifically oriented towards Web environments: 
Fig. 14 shows that only one of the analyzed works [50] is proposing some techniques that could be useful to address aspects as interfaces design for Web projects, like Storyboards or Personas. These techniques might, at the same time, help address aspects like interface customization per profile and complex navigation, together with achieving some of the goals of the Requirements Development process area of CMMI maturity level 3. The rest of the studied papers are not proposing any technique to tackle this specific Web characteristic.

In contrast, Fig. 15 shows that most of the studies provide Agile techniques that suit the specific needs of Web systems in relation to early delivery and adaptation to changes and, at the same, they comply with CMMI goals. These techniques are essentially based on Scrum or XP practices, or even a combination of these two methodologies.

As a main conclusion for the Web dimension, we can state that specific works for Web environment are suggesting techniques to fit some of the special characteristics of Web systems, but not all of them. There is therefore a lack of a comprehensive work that map all the Web special characteristics with Agile techniques able to fulfill all CMMI maturity levels' goals.

\section{Conclusions and future work}

The present study aims to evaluate the actual status of the relation between Agile practices and techniques and CMMI-DEV model in Web environment systems, by starting with a systematic review of the existent literature and a selection of relevant works. As mentioned in Section 4.1, the general question to answer is whether an Agile approach is feasible enough to reach a certain maturity model in a Web-based environment. Three main objectives are heading the review to answer that question:

- Identify the state-of-the-art.

- Recognize the suggested solutions.

- Define a characterization schema.

With regard to the first objective, we can argue that only six approaches $[50,1,52,51,39,46]$ specifically discuss Web Systems, CMMI and Agile. This means that, although the current number of papers on the topic is quite low, most of the existing works have been published in the last 5 years. This might point to a new and growing line of research within the fields of Agile and maturity models. Nevertheless, due to the small amount of published research, the conclusions stated after carrying out our work might be seen as preliminary and should be confirmed by further research.

From the analyzed studies, the work by of Torrecilla et al. is based on the special characteristics of Web systems and centers on CMMI maturity levels 2 and 3. The study by Aggarwal et al. includes an example of a Web company implementing CMMI principles by using Agile practices. Tuan and Thang introduce a case study; a CMMI certified company that develops Web systems and uses Agile techniques to show the process implementation. Besides, the work by Pino et al. presents two case studies concerning the process improvements of two companies developing Web systems, one of them standing for the process of being CMMI level 2 certified. Finally, the paper by Smite and Gencel provides the results of a Web project that an Agile CMMI level 5 certified company carries out.

As it is known, Web projects differ from classic development projects [31,19,21,15,4,41,42,28], as they include, among others, concepts such as adapting interfaces, complex navigation, increased security and maintenance requirements, quick delivery, reduced timeto-market and adaptation to undefined requirements. The absence of a consistent and detailed Agile approach that could help an organization developing Web systems achieve a certain CMMI maturity level is seen as a main gap in today's "state-of-the-art" that could be filled in with further research.
As the second objective concerns, we can basically identify four types of works according to the results of the analysis:

- Theoretical studies about Agile compatibility with a certain CMMI maturity level, with or without a case study testing conclusions: $[50,51]$.

- Experience reports from certified CMMI companies using or trying to adopt Agile: [46,52].

- Experience reports from Agile companies trying to reach a certain CMMI level: [39].

- Other papers considering relations between Web systems, CMMI and Agile: [1].

In general, the assessed theoretical studies cover a deep testing on how the Agile approach can fulfill the goal of specific and generic practices of the examined process areas, on Web development environments. Moreover, the experience reports present a medium or low analysis of the compliance of practices that use Agile methods, focusing on the advantages on the lessons learned.

Finally, the third objective is met after conducting the review, following the approach described in Section 4. Based on the results, the selected works are analyzed using a characterization schema in order to make the comparison among them easier. This allows reaching objective three. This paper includes, in Section 5, a brief summary of each of the analyzed studies and results obtained from applying the characterization schema. Later, a brief evaluation of the overall results is presented in Section 6.

As previously stated, the general research question was structured into 5 research questions. Based on the results of the study, some arguments can be provided to answer them, as shown below:

- $R Q 1$ : This question tries to assess the "Compatibility" dimension. The results of our analysis identify approaches coming from both Agile and CMMI areas. This shows that, despite these fields can be seen as opposite, there is already a relations between both approaches as well as a mutual interest in each other. This fact makes us believe that a link among them can be both useful and desirable for Web development projects.

- RQ2: This question tries to assess the "Compliance" dimension. In our study, we have identified two approaches that have been used in order to validate "maturity" in an Agile approach on Web development environments: Theoretical and empirical (mainly selfassessment) assessment. This element points to a main lack on the existing literature: a real Web-developing company undergoing a formal CMMI assessment by means only of Agile techniques.

- RQ3: This question analyzes the "Experience" dimension. As it can be noticed, most of the researched studies include some kind of case studies and empirical tests, that point to the direction of Agile approaches feasibility. Nevertheless, we have not found any specific report of a CMMI assessment for a company developing Web systems only by means of Agile practices. Another important gap is that there is no work that presents at the same time a low level mapping between Agile practices and CMMI goals together with a practical evaluation of it, even based on self-assessment.

- RQ4: This question tests the "Maturity" dimension. It must be highlighted that most of the studies are focusing on CMMI maturity levels 2 and 3 (although one of the case studies reports a project from CMMI level 5 company). This also is in line with other reviews, not focused specifically on Web environments. In this case, the main gap is the absence of studies or mapping proposals for CMMI highest maturity levels.

- RQ5: The last question evaluates how Agile techniques can comply with CMMI goals and fit the special characteristics of Web projects. The result is that one of the studies advances techniques to address Navigation and Interface design in Web environments (like Personas and Storyboards), although the quick adaptation to changes, quick delivery of changes and reduction of feedback 
loops can be faced up with Scrum, XP techniques or a combination of both approaches. Nevertheless, a work providing a clear link among Agile techniques, Web characteristics and CMMI goals is also missing.

Additionally, the results of the review remark that the main Agile approach used in the literature is Scrum, either alone or combined with other Agile techniques (mainly XP). This fact confirms the common usage and popularity of this Agile methodology [38].

We can state, from the conclusions of some of the works such as [51] that neither Scrum nor XP by themselves can achieve all CMMI maturity levels in Web environments, but they can be used as a starting point to develop an Agile framework to achieve them.

As an example out of the Web development world, we found the work of [30], which includes a reference to a complete Scrum-based Agile model that fulfills the majority of CMMI maturity levels 2 and 3 objectives and excludes some organizational areas. Identifying, on a similar way to this work, a complete Agile framework (focused on Scrum and going beyond it) covering the goals of all specific and generic areas at every maturity level which could help organizations evolve on CMMI maturity levels, will constitute a further research line.

Coming back to our principal question, and as a general conclusion, it must be stated that the results of our study lead towards feasibility to use Agile methods to reach a certain CMMI-DEV maturity level in Web Environments. However, they are neither conclusive nor definitive, and further research should be useful, mainly on how to get CMMI-DEV higher levels with Agile techniques.

Although during our review some papers analyzing the relation between Agile and ISO/IEC processes improvement standards (like ISO 15504 or ISO 12207) have been identified [29] and there are some research groups working on this particular question [36], we have not been able of find any work linking these topics with Web Engineering. Besides, as stated before, during our review process we have not been able to gather any work analyzing the relation among Agile, Web Engineering and CMMI on its continuous representation. Lastly, despite we were able to identify papers studying Agile Maturity Models like [48] and [49], none of them are providing the Web dimension. As a conclusion, these three aspects (the relation among Agile, Web Engineering and ISO/IEC process standards, CMMI continuous representation and Agile Maturity Models) remain as three open research areas to further development.

Finally, as this research field is relatively new, we expect that in a recent future new work may appear proposing innovative Agile models and including detailed reports specifying how to institutionalize these models, via CMMI models, so as to enhance organizations produce better software and satisfy customers' expectations. The fact of having an increased number of published papers in the last years also reinforces this conclusion.

\section{Acknowledgments}

This research has been supported by the MeGUS project (TIN201346928-C3-3-R) of the Ministerio de Ciencia e Innovación, Spain. We would also like to thank Dr. Jörg Thomaschewski for his useful and helpful comments.

\section{Annex A. References to fully-analyzed papers}

r1 - López-Lira Hinojo, F.J. 2014. "Agile, CMMI®, RUP®, ISO/IEC $12207 . . .:$ is there a method in this madness?". ACM SIGSOFT Software Engineering Notes, 39(2), 1-5.

r2 - Selleri Silva, F. S.; Soares, F. S. F.; Peres, A. L.; de Azevedo, I. M.; Pinto, P. P.; de Lemos Meira, S. R. 2014. "A Reference Model for Agile Quality Assurance: Combining Agile Methodologies and Maturity Models". In proceedings of the 9th International Con- ference on Quality of Information and Communications Technology (QUATIC) (pp. 139-144). 2014. IEEE.

r3 - Hamouda, A. E. D. 2014. "Using Agile Story Points as an Estimation Technique in CMMI Organizations". In proceedings of Agile Conference (AGILE), 2014 (pp. 16-23). IEEE.

r4 - Bougroun, Z.; Zeaaraoui, A. Bouchentouf, T. 2014. "The projection of the specific practices of the third level of CMMI model in Agile methods: Scrum, XP and Kanban". In proceedings of Information Science and Technology (CIST), 2014 Third IEEE International Colloquium in (pp. 174-179). IEEE.

r5 - Garzás, J.; Paulk, M. C. 2013. "A case study of software process improvement with CMMI-DEV and Scrum in Spanish companies". Journal of Software: Evolution and Process, 25(12), $1325-1333$.

r6 - Miller, J.R.; Haddad, H.M. 2012. "Challenges Faced While Simultaneously Implementing CMMI and Scrum: A Case Study in the Tax Preparation Software Industry". In proceedings of 9th Information Technology: New Generations (Las Vegas, Nevada, USA 16-18 Apr. 2012). ITNG '12. IEEE.

r7 - Lukasiewicz, K.; Miler, J. 2012. "Improving Agility and Discipline of Software Development with the Scrum and CMMI," Software, IET, vol. 6, no. 5, pp. 416, 422, October 2012.

r8 - Zhang Lina; Shao Dan. 2012. "Research on Combining Scrum with CMMI in Small and Medium Organizations". In proceedings of 2012 International Conference on Computer Science and Electronics Engineering (Hangzhou, China 23-25 Mar. 2012). ICCSEE '12. IEEE.

r9 - Morales Trujillo, M.; Oktaba, H.; Pino, F. J.; Orozco, M. J. 2011. "Applying Agile and Lean Practices in a Software Development Project into a CMMI Organization". In proceedings of the 12th International Conference on Product-focused Software Process Improvement (Torre Cane, Italy 20-22 Jun. 2011). PROFES ' 11. Springer.

r10 - Cohan, S.; Glazer, H. 2009. "An Agile Development Team's Quest for CMMI Maturity level 5". In proceedings of Agile Conference 2009 (Chicago, IL, USA 24-28 Aug. 2009). AGILE '09. IEEE.

r11 - Jakobsen, C.R.; Sutherland, J. 2009. "Scrum and CMMI Going from Good to Great". In proceedings of Agile Conference 2009 (Chicago, IL, USA 24-28 Aug. 2009). AGILE '09. IEEE.

r12 - Díaz, J.; Garbajosa, J.; Calvo-Manzano, J.A. 2009. "Mapping CMMI level 2 to Scrum Practices: An Experience Report". Jan. 2009. SPI 42 93-104.

r13 - Omran, A. 2008. "AGILE CMMI from SMEs Perspective". In proceedings of 3rd International Conference on Information and Communication Technologies: From Theory to Applications. (Damascus, Syria 7-11 Apr. 2008). ICTTA 2008.

r14 - Jakobsen, C. R.; Johnson, K. A. 2008. "Mature Agile With a Twist of CMMI”. Aug. 2008. In proceeding of Agile Conference 2008 (Toronto, Canada 04-08 Aug. 2008). AGILE ‘08. IEEE.

r15 - Sutherland, J. et al. 2008. "Scrum and CMMI level 5: The Magic Potion for Code Warriors". Jan. 2008. In proceeding of the 41st annual Hawaii International Conference on System Sciences 2008 (Hawaii, USA 07-10 Jan. 2008). HICSS '08. IEEE.

r16 - Marcal, A.S.C.; de Freitas, B.C.C.; Furtado Soares, F.S.; Belchior, A.D. 2008. "Blending Scrum Practices and CMMI Project Management Process Areas". 2008. ISSE 4. 17-29.

r17 - Navarrete, F.; Botella, P.; Franch, X. 2006. "An approach to reconcile the Agile and CMMI contexts in product line development". In proceedings of the 1st International Workshop on Agile Product Line Engineering (APLE'06).

r18 - Baker, S. W. 2006. "Formalizing Agility, Part 2: How an Agile Organization Embraced the CMMI". Jul. 2006. In proceeding of Agile Conference 2006 (Minneapolis, USA 23-28 July 2006). AGILE ‘06. IEEE. 
r19 - Baker, S. W. 2005. "Formalizing Agility: An Agile Organization's Journey Toward CMMI Accreditation”. Jul. 2005. In proceeding of Agile Development Conference 2005 (Denver, CO, USA 2429 July 2005). ADC '05. IEEE.

r20 - Maller, P.; Ochoa, C.; Silva, J. 2005. "Lightening the Software Production Process in a CMM level 5 Framework". Latin America Transactions, IEEE (Revista IEEE América Latina), vol. 3, no. 1, pp. 15, 22, March 2005.

r21 - Anderson, D. J. 2005. "Stretching Agile to fit CMMI level 3-the story of creating MSF for CMMI ${ }^{\circledR}$ Process Improvement at Microsoft Corporation". In proceedings of Agile Conference, 2005. Proceedings (pp. 193-201). IEEE.

r22 - Bos, E.; Vriens, C. 2004. “An Agile CMM”. In proceedings of 4th Conference on Extreme Programming and Agile Methods. (Calgary, Canada Aug. 2004). XP/Agile Universe 2004. Springer. r23 - Nawrocki, J.; Jasiñski, M.; Walter, B.; Wojciechowski, A. 2002. "Extreme programming modified: embrace requirements engineering practices". In Requirements Engineering, 2002. Proceedings. IEEE Joint International Conference on (pp. 303-310). IEEE.

r24 - Paulk, M. C. 2001. "Extreme programming from a CMM perspective”. Software, IEEE, 18(6), 19-26.

\section{Annex B. Characterization of fully-analyzed papers}

Table B.1 Presents a short summary of the different fully-analyzed papers.

Table B.2 Presents the evaluation results of each of the studies against the defined characterization schema.

Table B.1

Summary of fully-analyzed papers.

\begin{tabular}{|c|c|}
\hline Study & Analysis \\
\hline r1 & $\begin{array}{l}\text { This paper presents a two-dimension model in order to compare the different available methods, both } \\
\text { disciplined and Agile. Methodologies and models like CMMI and PMBOK are assessed from a disciplined } \\
\text { point of view. Techniques like XP, Scrum and Agile Unified Process are analyzed from Agile point of view. The } \\
\text { methods are assessed against the presented model, but not one among each other. All the study is presented } \\
\text { in a theoretical way, without experiments or case studies. It states that AUP can be suitable to support } \\
\text { change management, covering one of the characteristics from a Web point of view }\end{array}$ \\
\hline r2 & $\begin{array}{l}\text { This work studies how feasible is to use Agile techniques to meet the goals of the CMMI process areas linked to } \\
\text { Quality Assurance in its different maturity levels, by means of defining an Agile Quality Assurance Maturity } \\
\text { Model with a similar approach to that of CMMI. It also offers the results of a survey on the analyzed topic }\end{array}$ \\
\hline r3 & $\begin{array}{l}\text { This paper presents a methodology that introduces estimation based on Agile story points and applied to four } \\
\text { projects of a CMMI level } 3 \text { company from an organizational point of view. The results show an improvement } \\
\text { on estimations. Despite the paper only focuses on a specific issue (project estimation), the proposed } \\
\text { techniques might be useful in Web environments, as they could help to quickly estimate new requirements } \\
\text { appearing during projects }\end{array}$ \\
\hline r4 & $\begin{array}{l}\text { This paper maps in detail the special goals of CMMI maturity level } 3 \text { process areas to the proposed practices of } \\
\text { three Agile methods: Scrum, eXtreme Programming and Kanban. The study evaluates which technique } \\
\text { proposed by the different Agile methods can meet each of the goals by giving a coverage percentage. It } \\
\text { concludes that the three methods are complementary and can reach a large number of CMMI level } 3 \text { goals. } \\
\text { Finally, it provides a case study concerning CMMI level } 3 \text { in a particular company using Agile processes to } \\
\text { validate the proposal }\end{array}$ \\
\hline r5 & $\begin{array}{l}\text { This case study on several Spanish IT companies describes the relation between CMMI-DEV level } 2 \text { and Scrum, } \\
\text { with the aim of assessing whether Scrum can help implement CMMI process model. It concludes that Scrum } \\
\text { enables improving the different process areas of CMMI maturity level } 2\end{array}$ \\
\hline r6 & $\begin{array}{l}\text { This case study illustrates how a company started the implementation of an Agile software development } \\
\text { methodology based on Scrum and a formal assessment process at CMMI maturity level 2, at the same time. } \\
\text { The company works on the tax preparation market and there is no reference of specific Web systems applied } \\
\text { to the project. This short paper describes the project, but it does not specify how each of the goals of CMMI } \\
\text { processes is achieved. One of the strong points of the work is that the company reaches the maturity level } \\
\text { via a formal SCAMPI assessment }\end{array}$ \\
\hline r7 & $\begin{array}{l}\text { This study presents a model that maps the specific processes of CMMI levels } 2 \text { and } 3 \text { to Scrum practices. Model } \\
\text { C-S covers } 123 \text { practices, but excludes some of the areas associated with the organizational structure. } \\
\text { Besides, the paper describes which practices are fully covered, partially covered or not covered at all. It } \\
\text { suggests that ad-hoc extensions should be utilized for those practices that Scrum standard practices } \\
\text { uncover. Besides, it includes a diagnostic questionnaire, a selection algorithm, an application process and a } \\
\text { tool, which are further described in the paper. To conclude, the work presents two case studies in order to } \\
\text { validate the model }\end{array}$ \\
\hline r8 & $\begin{array}{l}\text { This work assesses how feasible is to combine Scrum and CMMI for small and medium companies from a } \\
\text { theoretical point of view. It analyzes in depth some process areas, compares both Scrum and CMMI } \\
\text { approaches, and suggests which one should be the most useful to achieve the set goals }\end{array}$ \\
\hline r9 & $\begin{array}{l}\text { This work presents an experience report showing how a certified CMMI level } 5 \text { organization modifies its } \\
\text { development process, including Agile practices, in order to improve agility. It leads towards an increase in } \\
\text { both the quality of its products and customers' satisfaction. The introduced Agile approaches are Scrum, } \\
\text { Lean and TDD. The work also describes the process of including the selected techniques and results, as well } \\
\text { as provides empirical evidence of using Agile in a CMMI certified organization }\end{array}$ \\
\hline r10 & $\begin{array}{l}\text { This study relates the practical experience of an Agile company on its aim to achieve CMMI maturity level 5, by } \\
\text { using principally XP proposed practices. This experience report narrates how the company strengthens its } \\
\text { Agile practices with Agile project management techniques in order to self-prepare for a formal SCAMPI } \\
\text { assessment. It also defines useful metrics that allow continuous improvement }\end{array}$ \\
\hline
\end{tabular}




\begin{tabular}{|c|c|}
\hline Study & Analysis \\
\hline r11 & $\begin{array}{l}\text { This work reports an experience of how a certified CMMI level } 5 \text { organization introduces Scrum and Lean } \\
\text { practices with the aim of developing agility and continuous improvement. It also compares the results of the } \\
\text { company's two projects obtained by Agile practices with the average performance of the company, showing } \\
\text { great improvements, both in productivity and in the average time to fix bugs. }\end{array}$ \\
\hline r12 & $\begin{array}{l}\text { This work studies how to map Scrum practices to certain CMMI maturity level } 2 \text { process areas: Project } \\
\text { Planning (PP), Project Monitoring and Control (PMC) and Requirements Management (REM). Besides, it } \\
\text { analyzes every specific practice of such process areas, by verifying whether Scrum standard practices can } \\
\text { achieve the goal and identify the gaps between both models. Therefore, it presents a case study as a formal } \\
\text { assessment of an internal project. }\end{array}$ \\
\hline r13 & $\begin{array}{l}\text { This paper analyzes how small and medium enterprises can adopt Agile methodologies following the CMMI } \\
\text { model, in order to benefit from both areas. The selected Agile approach of this work is eXtreme } \\
\text { Programming. It particularly presents a theoretical study that evaluates, in each of the CMMI process areas, } \\
\text { whether XP standard practices can fulfill or not the goals as well as identify gaps. The paper does not include } \\
\text { any case study to test the proposed model }\end{array}$ \\
\hline r14 & $\begin{array}{l}\text { This paper not only highlights the experience of a certified CMMI level } 5 \text { company assuming Scrum practices, } \\
\text { but also proposes some practices, based on the experience, to formalize and systematize Agile practices in } \\
\text { an organization, mainly at maturity levels } 2 \text { and } 3 \text {. The suggested practices focus on initial project planning, } \\
\text { risk management, quality assurance and test and configuration management, and propose certain practices } \\
\text { for Agile projects to mature. }\end{array}$ \\
\hline r15 & $\begin{array}{l}\text { This work explains how a certified CMMI level } 5 \text { enterprise utilizes Agile and Lean practices. The company } \\
\text { applies a Lean approach to identify improvement areas and decides to start with } 4 \text { pilot projects based on } \\
\text { Scrum and early testing techniques. According to the results, it copes with } 12 \text { generic practices associated } \\
\text { with CMMI maturity levels } 2 \text { and } 3 \text { to show how they can help an organization use Agile Methods. }\end{array}$ \\
\hline r16 & $\begin{array}{l}\text { This paper assesses whether Scrum standard practices can achieve the objectives of specific practices regarding } \\
\text { Project Management Process Areas of CMMI maturity levels 2, } 3 \text { and } 4 \text {. It presents a deep theoretical analysis } \\
\text { of } 22 \text { of these specific practices and their relation with Scrum techniques, and it also determines if the goals } \\
\text { are fully, partially or non-achieved at all. It does not consider a case study to assess conclusions }\end{array}$ \\
\hline r17 & $\begin{array}{l}\text { This study presents a preliminary analysis on the compatibility of Agile and CMMI approaches in the software } \\
\text { product line domains, with the aim of taking the best of both. The paper presents a mapping between CMMI } \\
\text { process areas and product line practices as well as a mapping between the Agile principles derived from the } \\
\text { Agile manifesto and product line practice areas. The paper concludes that both approaches could be } \\
\text { compatible, specially focusing on the XP approach }\end{array}$ \\
\hline r18/r19 & $\begin{array}{l}\text { We have decided to analyze these two papers together because they present two parts of the same experience } \\
\text { (how an Agile company successfully passes through two formal assessment processes at CMMI maturity } \\
\text { levels } 2 \text { and 3). They show how the company progresses on the use of Agile methods and how it prepares the } \\
\text { formal assessments of CMMI maturity levels } 2 \text { and 3, as well as a summary of the evaluation results. }\end{array}$ \\
\hline r20 & $\begin{array}{l}\text { This paper offers a proposal, attending to the combined use of Scrum and eXtreme Programming, so as to } \\
\text { achieve CMMI maturity level 5. The starting point of the study will be organizations that have already been } \\
\text { assessed as CMMI maturity level } 5 \text { and work on small development projects. It describes the process areas, } \\
\text { although it gives no details on the specific or generic practices of each area. The proposed model is tested by } \\
\text { means of three pilot projects that bring about quality, time and cost improvements }\end{array}$ \\
\hline r21 & $\begin{array}{l}\text { This study presents, in the form of an industry report, the process of a Microsoft product team combining } \\
\text { in-house Agile practices with Deming's approach to define a lightweight framework to fit the requirements } \\
\text { of CMMI maturity level } 3\end{array}$ \\
\hline r22 & $\begin{array}{l}\text { This work presents an experience report on how a company achieved CMMI level } 2 \text { by means of a combined } \\
\text { used of Scrum and XP and obtained successful results after a formal assessment at that maturity level. It } \\
\text { outlines the areas involved in the process and how Agile methods helped achieve both goals and results of } \\
\text { this formal assessment }\end{array}$ \\
\hline r23 & $\begin{array}{l}\text { This paper assesses eXtreme Programming from the point of view of CMMI and Sommerville-Sawyer model } \\
\text { and proposes some modifications to the Agile method. The authors recommend some changes to XP that } \\
\text { will keep its agility, although allowing reaching CMMI maturity level } 2 \text { goals }\end{array}$ \\
\hline r24 & $\begin{array}{l}\text { This study analyzes the practices proposed by eXtreme Programming and CMMI levels } 2 \text { and } 3 \text { process areas } \\
\text { from a theoretical point of view. It concludes that XP can fulfill most level } 2 \text { practices and cover some of level } \\
\text { 3. It also states that XP will be more productive whenever the project size remains small }\end{array}$ \\
\hline
\end{tabular}


Table B.2

Characterization of studies.

\begin{tabular}{|c|c|c|c|c|c|c|c|c|c|c|c|c|c|}
\hline Dimen. & Indicator & {$[\mathrm{r} 1]$} & [r2] & {$[\mathrm{r} 3]$} & {$[\mathrm{r} 4]$} & {$[\mathrm{r} 5]$} & [r6] & [r7] & {$[\mathrm{r} 8]$} & [r9] & {$[\mathrm{r} 10]$} & [r11] & [r12] \\
\hline \multirow[t]{3}{*}{ Compatibility } & $\begin{array}{l}\text { State-of-the-art } \\
\text { analysis }\end{array}$ & Low & Low & Low & Medium & Medium & Low & High & Low & Low & Low & Low & High \\
\hline & Starting point & Both & Agile & Agile & Both & Both & Both & Both & Both & CMMI & Agile & CMMI & Agile \\
\hline & Approaches & $\begin{array}{l}\text { Scrum XP } \\
\text { AUP }\end{array}$ & $\begin{array}{l}\text { Scrum, XP and } \\
\text { ad-hoc } \\
\text { extension }\end{array}$ & Agile estimating & $\begin{array}{l}\text { Scrum, XP, } \\
\text { Kanban }\end{array}$ & Scrum & Scrum & $\begin{array}{l}\text { Scrum and } \\
\text { ad-hoc } \\
\text { extension }\end{array}$ & Scrum & $\begin{array}{l}\text { Scrum, Lean } \\
\text { and TDD }\end{array}$ & $\begin{array}{l}\text { XP and Agile } \\
\text { Project Mgmt. }\end{array}$ & $\begin{array}{l}\text { Scrum and } \\
\text { Lean }\end{array}$ & Scrum \\
\hline \multirow[t]{2}{*}{ Compliance } & Assessment & No assess. & No assess. & No assess. & Theoretical & Empirical & Formal assess. & Theoretical & Theoretical & Empirical & Formal assess. & Formal assess. & Empirical \\
\hline & Analysis & $\mathrm{N} / \mathrm{A}$ & $\mathrm{N} / \mathrm{A}$ & $\mathrm{N} / \mathrm{A}$ & Deep & Deep & Low & Deep & Low & Low & Low & Low & Deep \\
\hline \multirow[t]{4}{*}{ Experience } & $\begin{array}{l}\text { Experiment/case } \\
\text { studies }\end{array}$ & No & No & Yes & Yes & Yes & Yes & Yes & No & Yes & Yes & Yes & Yes \\
\hline & $\begin{array}{l}\text { Size of organization } \\
\text { / project }\end{array}$ & $\mathrm{N} / \mathrm{A}$ & $\mathrm{N} / \mathrm{A}$ & Medium & Medium & Medium & Medium & Medium & $\mathrm{N} / \mathrm{A}$ & Medium & Large & Large & Small \\
\hline & Number of projects & 0 & 0 & 4 & 1 & 12 & 1 & 2 & 0 & 1 & No details & 2 & 1 \\
\hline & $\begin{array}{l}\text { Format } \\
\text { Type }\end{array}$ & $\begin{array}{l}\text { Short paper } \\
\text { Journal }\end{array}$ & $\begin{array}{l}\text { Short paper } \\
\text { Int. Conf. }\end{array}$ & $\begin{array}{l}\text { Paper } \\
\text { Int. Conf. }\end{array}$ & $\begin{array}{l}\text { Short paper } \\
\text { Int. Conf. }\end{array}$ & $\begin{array}{l}\text { Paper } \\
\text { Journal }\end{array}$ & $\begin{array}{l}\text { Short paper } \\
\text { Int. Conf. }\end{array}$ & $\begin{array}{l}\text { Short paper } \\
\text { Journal }\end{array}$ & $\begin{array}{l}\text { Short paper } \\
\text { Int. Conf. }\end{array}$ & $\begin{array}{l}\text { Paper } \\
\text { Int. Conf. }\end{array}$ & $\begin{array}{l}\text { Short paper } \\
\text { Int. Conf. }\end{array}$ & $\begin{array}{l}\text { Short paper } \\
\text { Int. Conf. }\end{array}$ & $\begin{array}{l}\text { Paper } \\
\text { Journal }\end{array}$ \\
\hline \multirow[t]{2}{*}{ Maturity } & Maturity level & No details & No details & 3 & 3 & 2 & 2 & 3 & No details & 5 & 5 & 5 & 2 \\
\hline & Coverage level & No details & No details & No details & Full & Full & No details & Partial & No details & No details & No details & No details & Partial \\
\hline \multirow[t]{2}{*}{ Web } & $\begin{array}{c}\text { Navigation \& } \\
\text { interfaces }\end{array}$ & No details & No details & No details & No details & No details & No details & No details & No details & No details & No details & No details & No details \\
\hline & $\begin{array}{l}\text { Delivery \& } \\
\text { Adaptation to } \\
\text { changes }\end{array}$ & $\begin{array}{l}\text { Scrum, XP, } \\
\text { AUP }\end{array}$ & Scrum, XP & Agile estimating & $\begin{array}{l}\text { Scrum, XP, } \\
\text { Kanban }\end{array}$ & No details & No details & No details & No details & Scrum & $\begin{array}{l}\text { Agile Project } \\
\text { Mgmt. }\end{array}$ & No details & Scrum \\
\hline Dimen. & Indicator & [r13] & [r14] & [r15] & [r16] & [r17] & [r18] & [r19] & [r20] & [r21] & [r22] & [r23] & {$[\mathrm{r} 24]$} \\
\hline \multirow[t]{3}{*}{ Compatibility } & $\begin{array}{l}\text { State-of-the-art } \\
\text { analysis }\end{array}$ & Low & Low & Low & High & Low & Low & Low & Medium & Low & Low & Low & Low \\
\hline & Starting point & Both & CMMI & CMMI & Agile & CMMI & Agile & Agile & CMMI & Agile & Agile & Agile & Agile \\
\hline & Approaches & $\mathrm{XP}$ & Scrum & Scrum and Lean & Scrum & $\mathrm{XP}$ & $\begin{array}{l}\mathrm{XP} \text { and } \\
\text { ad-hoc } \\
\text { extension }\end{array}$ & $\begin{array}{l}\mathrm{XP} \text { and } \\
\text { ad-hoc } \\
\text { extension }\end{array}$ & Scrum and $\mathrm{XP}$ & $\begin{array}{l}\text { Custom Agile } \\
\text { methods }\end{array}$ & Scrum and XP & $\mathrm{XP}$ & XP \\
\hline \multirow[t]{2}{*}{ Compliance } & Assessment & Theoretical & Formal assess. & Formal assess. & Theoretical & Theoretical & Formal assess. & Formal assess. & Empirical & Empirical & Formal assess. & Theoretical & Theoretical \\
\hline & Analysis & Medium & Low & Low & Deep & Low & Low & Low & Medium & Low & Medium & Medium & Medium \\
\hline \multirow[t]{4}{*}{ Experience } & $\begin{array}{l}\text { Experiment/Case } \\
\text { studies }\end{array}$ & No & Yes & Yes & No & No & Yes & Yes & Yes & Yes & Yes & No & No \\
\hline & $\begin{array}{l}\text { Size of organization } \\
\text { / project }\end{array}$ & $\mathrm{N} / \mathrm{A}$ & Large & Large & $\mathrm{N} / \mathrm{A}$ & $\mathrm{N} / \mathrm{A}$ & Large & Large & Small & Large & Medium & $\mathrm{N} / \mathrm{A}$ & $\mathrm{N} / \mathrm{A}$ \\
\hline & Number of projects & 0 & No details & 4 & 0 & 0 & No details & No details & 3 & 1 & 1 & 0 & 0 \\
\hline & $\begin{array}{l}\text { Format } \\
\text { Type }\end{array}$ & $\begin{array}{l}\text { Paper } \\
\text { Int. Conf. }\end{array}$ & $\begin{array}{l}\text { Short paper } \\
\text { Int. Conf. }\end{array}$ & $\begin{array}{l}\text { Short paper } \\
\text { Int. Conf. }\end{array}$ & $\begin{array}{l}\text { Paper } \\
\text { Journal }\end{array}$ & $\begin{array}{l}\text { Short paper } \\
\text { Int. Conf. }\end{array}$ & $\begin{array}{l}\text { Paper } \\
\text { Int. Conf. }\end{array}$ & $\begin{array}{l}\text { Paper } \\
\text { Int. Conf. }\end{array}$ & $\begin{array}{l}\text { Paper } \\
\text { Journal }\end{array}$ & $\begin{array}{l}\text { Paper } \\
\text { Int. Conf. }\end{array}$ & $\begin{array}{l}\text { Paper } \\
\text { Int. Conf. }\end{array}$ & $\begin{array}{l}\text { Paper } \\
\text { Int. Conf. }\end{array}$ & $\begin{array}{l}\text { Paper } \\
\text { Journal }\end{array}$ \\
\hline \multirow[t]{2}{*}{ Maturity } & Maturity level & 5 & 3 & 5 & 4 & No details & 3 & 2 & 5 & 3 & 2 & 2 & 3 \\
\hline & Coverage level & Partial & Partial & Partial & Partial & No details & No details & No details & Full & Full & Full & Partial & Partial \\
\hline \multirow[t]{2}{*}{ Web } & $\begin{array}{c}\text { Navigation \& } \\
\text { interfaces }\end{array}$ & No details & No details & No details & No details & No details & No details & No details & No details & No details & No details & No details & No details \\
\hline & $\begin{array}{l}\text { Delivery \& } \\
\text { adaptation to } \\
\text { changes }\end{array}$ & XP & Scrum & Scrum & Scrum & No details & No details & No details & Scrum XP & No details & Scrum XP & XP & XP \\
\hline
\end{tabular}




\section{References}

[1] S.K. Aggarwal, V. Deep, R. Singh, Speculation of CMMI in Agile methodology, in: Proceedings of Advances in Computing, Communications and Informatics (ICACCI, 2014 International Conference on, IEEE, 2014, pp. 226-230.

[2] D.J. Anderson, Kanban: Successful Evolutionary Change for Your Technology Business, Blue Hole Press, Sequim, WA: Boston, 2010.

[3] S.W. Ambler, Lessons in agility from Internet-based development, IEEE Softw. (2002) 66-73 March-Aprol 2002.

[4] C. Barry, M. Lang, A survey of multimedia and web development techniques and methodology usage, IEEE Multimed. (2001) 52-60 2001.

[5] K. Beck, C. Andres, Extreme Programming Explained: Embrace Change, second edition, Addison-Wesley, Boston, 2004.

[6] Beck, K. et al. 2001. "Manifesto for Agile Software Development". From http:// www.agilemanifesto.org (last accessed 03.15).

[7] A. Begel, N. Nagappan, "Usage and perceptions of Agile software development in an industrial context: an exploratory study, in: Proceedings of the 1st International Symposium on Empirical Software Engineering and Measurement, Madrid, Spain, September 21-27 2007,ESEM '07, IEEE, 2007.

[8] B. Boehm, R. Turner, Balancing Agility and Discipline: A Guide for the Perplexed, Addison-Wesley, Boston, 2003.

[9] S. Ceri, P. Fraternali, A. Bongio, Web modelling language (WebML): a modelling language for designing web sites, Comput. Netw. 33 (1-6) (2000) 137-157 Jun. 2000 .

[10] L. Chagas, D. Fernandes de Carvalho, A. Dias Lima, C. Magalhães Reis, Systematic literature review on the characteristics of Agile project management in the context of maturity models, Software Process Improvement and Capability Determination, 477, Springer International Publishing, 2014, pp. 177-189.

[11] Chrissis, M.B.; Konrad, M.; Shrum, S. 2003. "Introduction to CMMI". From http://www.informit.com/articles/article.aspx?p=98146\&seqNum=6 (last accessed 09.15).

[12] CMMI Institute. 2015. "Published Appraisal Results". From https://sas. cmmiinstitute.com/pars/ (accessed 09.20).

[13] CMMI Product Team, CMMI for Development, Version 1.3, Carnegie Mellon University, 2010 Nov. 2010 Technical report. From http://www.sei.cmu.edu/reports 10tr033.pdf (last accessed 03.15).

[14] A. Cockburn, Crystal Clear: A Human-Powered Methodology for Small Teams, Addison-Wesley, Boston, 2004.

[15] Y. Deshpande, S. Marugesan, A. Ginige, S. Hanse, D. Schawabe, M. Gaedke, B. White, Web engineering, J. Web Eng. 1 (1) (2002) 3-17 2002. Rinton Press.

[16] T. DeMarco, B. Boehm, The Agile methods fray, Computer (6) (2002) 90-92.

[17] T. Dybå, T. Dingsoyr, Empirical studies of Agile software development: a systematic review, Inf. Softw. Technol. 50 (9-10) (2008) 833-859.

[18] M.J. Escalona, G. Aragón, NDT: a model-driven approach for web requirements, IEEE Trans. Softw. Eng. 34 (3) (2008) 370-390 2008.

[19] M.J. Escalona, N. Koch, Requirements engineering for web applications: a comparative study, J. Web Eng. 2 (3) (2004) 193-212

[20] Escalona, M.J.; Mejías, M.; Torres, J. 2004. “Developing systems with NDT \& NDTTool". In: Proceedings of the 13th International Conference on Information Systems Development: Methods and Tools, Theory and Practice, Vilna, Lithuania (pp. 149-59).

[21] Escalona, M.J.; Mejías, M.; Torres, J. “Methodologies to develop Web Information Systems and Comparative Analysis". Informatik/Informatique. núm. 2/2002 de I/I.

[22] H. Glazer, et al., CMMI or Agile: Why Not Embrace Both!, Carnegie Mellon Unive sity, 2008 November 2008. From http://www.sei.cmu.edu/reports/08tn003.pdf (last accessed 03.15)

[23] L.T. Heeager, The Agile and the disciplined software approaches: combinable or just compatible?, Information Systems Development, Springer, New York, 2013 pp. 35-49.

[24] Herbleb, J. et al. 1994. "Benefits of CMM-based Software Process Improvement: Initial Results". August 1994. Carnegie Mellon University. From http://www.sei. cmu.edu/reports/94tr013.pdf (last accessed 03.15)

[25] J.B. Joshi, W.G. Aref, A. Ghafoor, E.H. Spafford, Security models for web-based applications, Commun. ACM 44 (2) (2001) 38-44.

[26] B. Kitchenham, et al., Systematic literature reviews in software engineering - a systematic literature review, Inf. Softw. Technol. 51 (2009) 7-15 2009.

[27] N. Koch, A. Knapp, G. Zhang, H. Baumeister, UML-based web engineering: an approach based on standards, Web Engineering: Modelling and Implementing Web Applications, Springer, 2008, pp. 157-191.
[28] N. Koch, A Comparative Study of Methods for Hypermedia Development, LudwigMaximilian-University, Munich, Germany, 1999 Technical report 9905.

[29] F.J. López-Lira Hinojo, Agile, CMMI ${ }^{\circledR}$, RUP ${ }^{\circledR}$, ISO/IEC 12207...: is there a method in this madness? ACM SIGSOFT Softw. Eng. Notes 39 (2) (2014) 1-5.

[30] K. Lukasiewicz, J. Miler, Improving agility and discipline of software development with the scrum and CMMI, Softw., IET 6 (5) (2012) 416, 422 October 2012.

[31] E. Mendes, N. Mosley, Web cost estimation: an introduction, Web Engineering: Principles and Techniques (2005) 182-202.

[32] Model Driven Web Engineering Workshop. Satellite Workshop of ICWE'2012 Conference. From http://mdwe2012.pst.ifi.lmu.de/ (last accessed 03.15).

[33] S. Murugesan, Y. Deshpande, S. Hansen, A. Ginige, Web engineering: a new discipline for development of web-based systems, Web Engineering, Springer, Berlin, Heidelberg, 2001, pp. 3-13.

[34] Object Management Group. 2014. "IFML: The Interaction Flow Modeling Language". From http://www.ifml.org/?page_id=99 (last accessed 03.15).

[35] L. Olsina, Building a web-based information system applying the hypermedia flexible process modelling strategy, in: Workshop on Hypermedia Development Processes, Methods and Models (Hypertext 98), Pittsburgh, USA, 1998.

[36] Z.B. Osorio Martínez, E. Irrazábal, J. Garzás, Toward improving Agile mantema: measurement, control and evaluation of maintenance projects in SMEs, in: 6th Iberian Conference on Information Systems and Technologies (CISTI), 2011, 15-18 June, 2011, pp. 1-6.

[37] M.C. Paulk, Extreme programming from a CMM perspective, Softw. IEEE 18 (6) (2001) 19-26.

[38] M. Pikkarainen, et al., The impact of Agile practices on communication in software development, Empirical Software Engineering, Springer, 2008, pp. 303-337. May. 2008.

[39] F.J. Pino, O. Pedreira, F. García, M.R. Luaces, M. Piattini, Using scrum to guide the execution of software process improvement in small organizations, J. Syst. Softw. 83 (10) (2010) 1662-1677.

[40] M. Poppendieck, T. Poppendieck, Lean Software Development. An Agile Toolkit, Addison-Wesley, Boston, 2003.

[41] R.S. Pressman, What a tangled web we weave, IEEE Softw. (2000) 18-21 JanuaryFebruary 2000.

[42] D.J. Reifer, "Web development: estimating quick-to-market software, IEEE Softw. (2000) 57-64 November-December.

[43] H. Ran, et al., Agile web development with web framework, in: Proceeding of 4th International Conference on Wireless Communications, Networking and Mobile Computing (Dalian, China, October 12-17 2008), WiCOM '08, IEEE, 2008.

[44] F. Selleri Silva, F. Santana Furtado Soares, A. Lima Peres, I. Monteiro de Azevedo, A. Vasconcelos, F. Kenji Kamei, S. Romero de Lemos Meira, Using CMMI together with Agile software development: a systematic review, Inf. Softw. Technol. 58 (2015) 20-43 February 2015.

[45] Shrum, S. 1999. "Continuous and Staged, a Choice of CMMI Representation". From http://www.sei.cmu.edu/library/abstracts/news-at-sei/spotlightdec99.cfm (last accessed 09.15).

[46] D. Smite, C. Gencel, Why a CMMI level 5 company fails to meet the deadlines?, Product-Focused Software Process Improvement, Springer, Berlin, Heidelberg, 2009, pp. 87-95.

[47] Sutherland, J.; Schwaber, K. 2011. "The Scrum Guide: The Definitive Guide to Scrum: The Rules of the Game". From http://www.scrum.org/Scrum-Guides (last accessed 03.15)

[48] T. Schweigert, D. Vohwinkel, M. Korsaa, R. Nevalainen, M. Biro, Agile maturity model: analysing Agile maturity characteristics from the SPICE perspective, J. Softw.: Evol. Process 26 (5) (2014) 513-520.

[49] T. Schweigert, D. Vohwinkel, M. Korsaa, R. Nevalainen, M. Biro, Agile maturity model: a synopsis as a first step to synthesis, Syst. Softw. Serv. Process Improv. 364 (2013) 214-227.

[50] C.J. Torrecilla Salinas, J. Sedeño, M.J. Escalona, M. Mejías, Mapping Agile practices to CMMI-DEV level 3 in web development environments, in: Information Systems Development: Transforming Organisations and Society through Information Systems (ISD2014 Proceedings), Varaždin, Croatia, 2014.

[51] C.J. Torrecilla Salinas, M.J. Escalona, M. Mejías, A scrum-based approach to CMM maturity level 2 in web development environments, in: Proceeding of International Conference on Information Integration and Web-based Applications \& Services 2012 (Bali, Indonesia December 3-5 2012). iiWAS, 12, ACM, 2012.

[52] N.N. Tuan, H.Q. Thang, Combining maturity with agility: lessons learnt from a case study, in: Proceedings of the 4th Symposium on Information and Communication Technology, ACM, 2013, pp. 267-274.

[53] Zotero. 2015. From www.zotero.org (last accessed 03.15). 